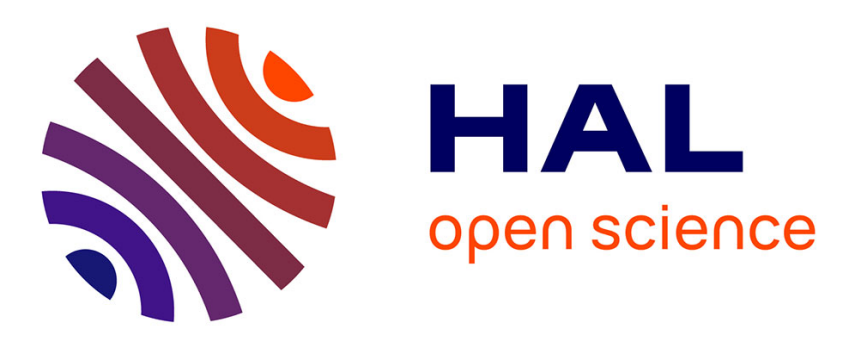

\title{
Oxytocin receptor agonist reduces perinatal brain damage by targeting microglia
}

Jerome Mairesse, Manuela Zinni, Julien Pansiot, Rahma Hassan-Abdi, Charlie

Demené, Marina Colella, Christiane Charriaut-Marlangue, Aline Rideau

Batista Novais, Mickael Tanter, Stéfania Maccari, et al.

\section{To cite this version:}

Jerome Mairesse, Manuela Zinni, Julien Pansiot, Rahma Hassan-Abdi, Charlie Demené, et al.. Oxytocin receptor agonist reduces perinatal brain damage by targeting microglia. Glia, 2019, 67 (2), pp.345-359. 10.1002/glia.23546 . hal-02375613

\section{HAL Id: hal-02375613 \\ https://hal.science/hal-02375613}

Submitted on 22 Nov 2019

HAL is a multi-disciplinary open access archive for the deposit and dissemination of scientific research documents, whether they are published or not. The documents may come from teaching and research institutions in France or abroad, or from public or private research centers.
L'archive ouverte pluridisciplinaire HAL, est destinée au dépôt et à la diffusion de documents scientifiques de niveau recherche, publiés ou non, émanant des établissements d'enseignement et de recherche français ou étrangers, des laboratoires publics ou privés. 


\section{Oxytocin receptor agonist reduces perinatal brain damage by targeting microglia}

Abbreviated title: Neuroinflammation and oxytocin

Jérôme Mairesse, ${ }^{1,2,3}$ Manuela Zinni, ${ }^{1}$ Julien Pansiot, ${ }^{1}$ Rahma Hassan-Abdi, ${ }^{1}$ Charlie

Demene, ${ }^{4}$ Marina Colella, ${ }^{1}$ Christiane Charriaut-Marlangue, ${ }^{1}$ Aline Rideau Batista Novais, ${ }^{1}$

Mickael Tanter, ${ }^{4}$ Stefania Maccari, ${ }^{5}$ Pierre Gressens, ${ }^{1,6}$ Daniel Vaiman, ${ }^{6,7}$ Nadia Soussi-

Yanicostas, ${ }^{1^{*}}$ Olivier Baud ${ }^{1,2,3,6^{*}}$

${ }^{1}$ PROTECT, Inserm U1141, Université Paris Diderot, Sorbonne Paris Cité, Paris, France.

${ }^{2}$ Division of Neonatology and Pediatric Intensive Care, Children's University Hospital of

Geneva, Geneva, Switzerland.

${ }^{3}$ Laboratory of Child Growth and Development, University of Geneva, Geneva, Switzerland.

${ }^{4}$ Institut Langevin, CNRS UMR 7587, Inserm U979, ESPCI Paris, PSL Research University, 75005 Paris, France.

${ }^{5}$ International Associated Laboratory (LIA) "Prenatal Stress and Neurodegenerative

Diseases", University of Lille 1 - CNRS UMR8576 and Sapienza University of Rome IRCCS Neuromed, France/ Italy.

${ }^{6}$ PremUP Foundation, 75014, Paris, France.

${ }^{7}$ Institut Cochin, Inserm U1016, UMR8104 CNRS, 75014 Paris, France.

* Olivier Baud and Nadia Soussi-Yanicostas contributed equally to the work.

\section{Corresponding author:}

Prof. Olivier BAUD, Division of Neonatology, Department of Pediatrics, University hospitals, Geneva, Switzerland.

Tel : +41795534204 Email: olivier.baud@hcuge.ch 


\section{Aknowledgments}

We thank Francesca Peri (EMBL, Heidelberg, Germany) for providing the Tg(ApoE:GFP) transgenic line, and $\operatorname{Dr} \mathrm{C}$. Laloux and the behavioral exploration platform for rodent (Federation of Neurosciences, Univ Lille, France). We thank Audrey Toulotte-Aebi for editing the manuscript.

\section{Funding}

This work was supported by Institut National de la Santé et de la Recherche Médicale (Inserm), Paris-Diderot University, National Center for Scientific Research (CNRS), the French National Research Agency (ANR-16-CE18-0010, ANR-14050HH), the European Research Council under the ERC Advanced grant (339244-FUSIMAGINE), and Fondation NRJ (Institut de France), Fondation PremUP and Fondation Paralysie Cérébrale. manuscript.

\section{Conflict of interest statement:}

None of the authors declare no conflict of interest.

\section{Number of words in:}

Abstract: 243

Introduction: 399

Materials and Methods: 1204

Results: 1570

Discussion: 1529

Legends: 1761

References: 1529

Total word count: 8235 
Raw data reported in the manuscript have been located in EMBL-European Bioinformatics Institute (EBI) E-MATB-6630 and E-MATB-6631, created 14 ${ }^{\text {th }}$ March 2018.

Keywords: microglia; oxytocin; perinatal stress; neuroprotection; myelination. 


\section{Abstract}

Prematurity and fetal growth restriction are frequent conditions associated with adverse neurocognitive outcomes. We have previously identified early deregulation of genes controlling neuroinflammation as a putative mechanism linking fetal growth restriction and abnormal trajectory of the developing brain. While the oxytocin system was also found to be impaired following adverse perinatal events, its role in the modulation of neuroinflammation in the developing brain is still unknown. We used a double-hit rat model of perinatal brain injury induced by gestational LPD and potentiated by postnatal injections of subliminal doses of IL1 $\beta$ and a zebrafish model of neuroinflammation. Effects of the treatment with carbetocin, a selective, long lasting and brain diffusible, oxytocin receptor agonist have been assessed using a combination of histological, molecular and functional tools in vivo and in vitro. In the double hit model, white matter inflammation, deficient myelination and behavioral deficits have been observed and the oxytocin system was impaired. Early postnatal supplementation with carbetocin alleviated microglial activation at both transcriptional and cellular levels and provided long-term neuroprotection. The central antiinflammatory effects of carbetocin have been shown in vivo in rat pups and in a zebrafish model of early-life neuroinflammation and reproduced in vitro on stimulated sorted primary microglial cell cultures from rats subjected to LPD. Carbetocin treatment was associated with beneficial effects on myelination, long-term intrinsic brain connectivity and behavior. Targeting oxytocin signaling in the developing brain may be an effective approach to prevent neuroinflammation - induced brain damage of perinatal origin. 


\section{Main points}

- A double-hit insult model of perinatal brain injury was found associated with low expression of Oxytocin, exacerbated microglial activation and defective myelination.

- A long-lasting Oxytocin receptor agonist regulates microglial reactivity and provides longterm neuroprotection. 


\section{Introduction}

Neurocognitive disabilities of perinatal origin remain a major burden on children, their families and society, underscoring the need to develop preventive strategies (Katz et al., 2013) (Christensen et al., 2014). Prematurity and fetal growth restriction (FGR), affecting $15-20 \%$ of all pregnancies, are the two leading causes of these learning disabilities and developmental behavioral disorders (Guellec et al., 2015; Hack et al., 2002; Jarvis et al., 2003).

Inflammation in the central nervous system plays a key role in the pathophysiology of perinatal brain damage observed in both animal models and human neonates (Hagberg, Gressens, \& Mallard, 2012). Although the mechanisms involved in inflammation-induced early brain injury remain unclear, recent evidences have shown that abnormal microglial activation can contribute to white matter damage, neurocognitive disabilities and neuropsychiatric disorders in children and adults (Leviton, Dammann, \& Durum, 2005; Rezaie \& Dean, 2002). These findings have been documented not only in models inducing neuroinflammation in neonatal animals (Favrais et al., 2011) but also in rat pups subjected to FGR, where extensive deregulation of genes controlling neuroinflammation in microglial cells has been recently reported (Rideau Batista Novais et al., 2016). Therefore, the regulation of neuroinflammation early in life offers a relevant approach to neuroprotection.

In addition to inflammation, perinatal stress associated with prematurity or FGR has been associated with disturbances in the hypothalamic-pituitary-adrenal (HPA) axis and with reduced oxytocin (OXT) expression in the hypothalamic paraventricular nucleus (Feldman, 2015; Lee, Brady, Shapiro, Dorsa, \& Koenig, 2007; Moisiadis \& Matthews, 2014). Oxytocin can facilitate a variety of social activities ranging from pair bonding to maternal behavior, which can be impaired by unexpected perinatal events, including prematurity (Alkozei, McMahon, \& Lahav, 2014). This hormone is also involved in the function of GABA neurons, in autistic-like behavior in adulthood (Romano, Tempesta, Micioni Di Bonaventura, \& Gaetani, 2015; Tyzio et al., 2014), and in social neuroprotection after cerebral ischemia (Karelina et al., 2011). Finally, OXT has peripheral and central anti-inflammatory effects in 
adult (Li, Wang, Wang, \& Wang, 2016; Yuan et al., 2016), but little is known about its impact on the developing brain.

Here, we hypothesize that OXT could influence microglial activation in response to perinatal brain injury and mitigate the ensuing damage. To address this issue, we used a rat model mimicking the most frequent perinatal injury affecting the human brain and a zebrafish model of microglia overactivation to investigate the effect of carbetocin, a long-lasting OXT receptor (OXTR) agonist, on neuroinflammation and its developmental consequences.

\section{Materials and Methods}

\section{Animals, diets and postnatal inflammatory challenge}

All experiments were carried out in compliance with INSERM ethical rules, approved by the institutional review board (Bichat-Robert Debré ethics committee, Paris, France, approval number 2010-13/676-0010) and following the rules of the European Communities Council Directive 2010/63/EU. Sprague-Dawley dams (Janvier SAS, France) were randomly divided into two groups according to their diet: a normal $22 \%$ protein diet (control, Ctl) or an isocaloric $9 \%$ protein diet (LPD) from the day of conception until delivery, as previously described(Zana-Taieb et al., 2015). At postnatal day 1 (P1) and P2, pups were injected intraperitoneally (i.p.) twice a day with PBS or carbetocin $\left(1 \mathrm{mg} / \mathrm{kg}, \mathrm{H}-5832\right.$, Bachem ${ }^{\circledR}$, Switzerland) for control animals whereas LPD animals received recombinant IL $1 \beta(20 \mu \mathrm{g} / \mathrm{kg}$, R\&D Systems, Minneapolis, MN) alone or in combination with carbetocin (1mg/kg).

\section{Neural Tissue Dissociation and Magnetic-Activated Cell Sorting}

Brains were collected for cell dissociation and microglial cell were enriched using a magneticbead-coupled antibody (anti-CD11b) extraction technique (MACS), according to the manufacturer's protocol (Miltenyi Biotec, Germany)(Rideau Batista Novais et al., 2016). Microglial cells were sorted at P2 (primary culture, 2 brains per sorting) or P4 (micro-array analysis, 1 brain per sorting). 
RNA Preparation, cDNA Synthesis, Microarray Hybridization, and Bioinformatics

\section{Analysis}

Total RNA was extracted from purified microglia of each P4 animal, cDNA synthesis and microarray hybridization were performed as previously described(Rideau Batista Novais et al., 2016). For microarray hybridization, labeled cRNA was generated using classical protocols for Affymetrix array hybridization. Three points per condition were analyzed using RaGene-2_0-st microarray hybridization, 36685 probes are examined and directly analyzed using Gene Set Enrichment Analysis (GSEA; http://software.broadinstitute.org/gsea/index.jsp) (Subramanian et al., 2005). The microarrays were also analyzed as networks built using string (http://string-db.org/). The numerical data from the network were then exported to Cytoscape for the hub genes analysis. To validate the microarray observations, qRT-PCR has been performed on 12 up or down regulated genes $(\mathrm{N}=8-10$ samples from two litters).

\section{RNA Purification for Real-Time PCR on cortical samples}

For qRT-PCR quantification, cortical samples were immediately snap-frozen in liquid nitrogen from 8 to 10 pups from three litters. Total RNA was extracted with the RNeasy mini kit (Qiagen, France) and one mg was subjected to reverse transcription using the IscriptTM cDNA synthesis kit (Bio-Rad, France). qRT-PCR was performed in duplicate for each sample as previously described (Favrais et al., 2011). Primers were designed using Primer3 software and manufactured by Eurofins Genomics (Germany). GAPDH was used as reference gene. Analyses were performed using Bio-Rad CFX Manager 3.0.

\section{Microglia primary culture}

Experiments were conducted in 3 separate experiments with a total of 9 control mothers (64 P2 pups) and 10 LPD mothers (66 P2 pups). After cell sorting microglia were cultured in DMEM F-12 medium (10\% FBS). After 48h Ctl and LPD cells were divided in four experimental groups for mRNA analysis and treated with 1) PBS, 2) IL1 $\beta(50 \mathrm{ng} / \mathrm{ml})+$ INFY 
(20ng/ml) (R\&D Systems, Minneapolis, MN) for $4 \mathrm{~h}, 3)$ carbetocin $(1 \mu \mathrm{g} / \mathrm{ml} \approx 1 \mu \mathrm{M})$ for $1 \mathrm{~h}$ plus IL1ß $(50 \mathrm{ng} / \mathrm{ml})+$ INFY $(20 \mathrm{ng} / \mathrm{ml})$ for $4 \mathrm{~h}, 4) \mathrm{L}-368,899$ (Tocris, France) $(2 \mu \mathrm{M})$ for 10 minutes plus carbetocin $(1 \mu \mathrm{g} / \mathrm{ml} \approx 1 \mu \mathrm{M})$ for $1 \mathrm{~h}$ and IL1 $\beta(50 \mathrm{ng} / \mathrm{ml})+\mathrm{INFY}(20 \mathrm{ng} / \mathrm{ml})$ for $4 \mathrm{~h}$. For morphological analysis, groups 1-3 were included in the analysis after 9h drug exposure.

For qRT-PCR total RNA was extracted using the NucleoSpin RNA Plus extraction kit (Macherey-Nagel, France). Reverse transcription and qPCR measurements were performed as described above with the Ribosomal protein L13 (Rpl13) and Hypoxanthine Phosphoribosyltransferase (Hprt) as reference genes.

Cytokines concentrations in cell culture medium were measured by multiplex Luminex assay (171K1002M Bio-Plex Pro Rat Cytokine TH1/TH2, Biorad, France).

For morphological analysis, after a 4\% PFA fixation, cells were stained with a goat anti-lba1 and $\mathrm{Iba} 1^{+}$cells were analyzed using a fluorescent microscope (Nikon Eclipse Ti-E). Between 190 and 243 single cells/group have been analyzed and the following morphological parameters have been evaluated: 1) Cells Area, 2) Cells perimeter, 3) Cells sphericity using the relation $4 \pi \times\left(\right.$ area/perimeter $\left.{ }^{2}\right)$. Control cells (Ctl, PBS) were divided in three size groups on the base of cells area: 1) $\left.\left.<31 \mu \mathrm{m}^{2}, 2\right) 31<\mu \mathrm{m}^{2}>45,3\right)>45 \mu \mathrm{m}^{2}$ and the percentage of cells for each size group and for each experimental condition was calculated.

\section{Immunohistochemistry}

In each experimental group, we studied 8 to 10 pups from at least two litters on postnatal days P4 for Iba1, and on P10 for MBP, APC and Olig2 as previously described (Rideau Batista Novais et al., 2016).

\section{Functional Ultrasound (fUS) Imaging of Intrinsic Brain Connectivity in Living Rats}

Resting state fUS imaging was performed at P28 on 7-9 rats from two litters in each group as previously described by Rideau et al., 2016, extending the number of brain area (ROI) from 10 to 20 (see Fig. 6A). 


\section{Behavioral assessment}

One-month old Control and LPD+IL1 $\beta$ rats (treated or not with carbetocin, 6 per group) were placed individually into the Open Field, $50 \times 50 \mathrm{~cm}$ square brightly illuminated (400 Ix) arena. The exploratory behavior of the animal was tracked using Ethovision video tracking equipment and software (Noldus, The Netherlands) for $10 \mathrm{~min}$.

Two-months old rats (9 to 11 animals per group) were tested using a 2-trial memory task between 9 am and 3 pm, in a Y-maze as previously described(Dellu, Mayo, Cherkaoui, Le Moal, \& Simon, 1992) with a 6 hours inter-trial interval between the $15 \mathrm{~min}$ acquisition and the 5 min retention phases.

\section{Zebrafish experiments}

Zebrafish were maintained at $26.5^{\circ} \mathrm{C}$ in $14 / 10$ light/dark cycles. Developmental stages were determined as hours post-fertilization (hpf) or days post-fertilization (dpf) as previously described (Kimmel, Ballard, Kimmel, Ullmann, \& Schilling, 1995). The transgenic line Tg[Apo-E-GFP] was previously described(Peri \& Nusslein-Volhard, 2008) and all experiments were approved by the French Animal Ethics Committee in accordance with the ethics statement $n^{\circ} 2012-15 / 676-0069$.

Dechorionated $24 \mathrm{hpf}$ embryos were first incubated in 12-well culture plates for 5 days with hydrocortisone $(1.3 \mu \mathrm{M})$. Then, carbetocin $(1 \mu \mathrm{M})$ was added to the hydrocortisone solution and embryos were incubated for an additional 48-hour period. As controls, embryos were treated with carbetocin alone, or E3 medium. All solutions were changed daily. All experiments were conducted on $8 \mathrm{dpf}$ larvae (Fig. 4A).

Specific mRNA levels (15 larvae for each batches) were evaluated after normalization with beta-actin mRNA.

Fluorescent images were captured using a Leica SP8 confocal scanning laser microscope (20x/0.75 objective) and an Olympus (40x/1.1 objective). Images were analyzed using both Imaris 8.4.0 (Bitplane Inc.) and Fiji 2.0.0 (NIH Fiji open-source) softwares. Quantifications were performed using images from three independent experiments. The surface, volume and 
sphericity $\left(\Psi=\frac{\pi^{\frac{1}{3}}\left(6 V_{p}\right)^{\frac{2}{3}}}{A_{p}}\right)$ of microglial cells were quantified using the Imaris MeasurementPro software (Bitplane Inc.). The speed (distance travelled per unit of time) and displacement (distance between first and last positions) of microglia processes were analyzed using the Imaris Filament tracer software (Bitplane Inc.).

\section{Statistical Analysis}

All data are reported as means \pm S.E.M. Statistical analysis of all data was performed using GraphPad PRISM version 6.0 (San Diego, CA). T-test was performed for two groups comparisons. For more than 2 groups, a one- or two- way ANOVA followed by a Newman Keul's post hoc multiple comparison tests was performed. For the open field analysis, comparison of activity between the various zones for the four experimental groups was performed using two-way ANOVA for repeated measure followed by Bonferroni multiple comparison tests. Significance was set at $\mathrm{P}<0.05$ for all tests. Detailed numbers, t-, F- and P-values were reported on supplementary Table 1.

\section{Results}

\section{Deregulation of OXT system and microglial activation in response to a double-hit} model of perinatal brain injury

We first refined a rat model based on a gestational low protein diet (LPD) inducing FGR (Rideau Batista Novais et al., 2016) by combining antenatal LPD and postnatal low-dose IL1 $\beta$ injections to mimic pro-inflammatory events commonly associated with brain damage and neurocognitive impairments (Leviton et al., 2013) (Fig. 1A). In this double-hit model, early imbalance towards excessive HPA-related hormones and lower expression of OXT was observed in the hypothalamus at P1 (Fig. 1B). OXTR gene expression was also found upregulated in hypothalamus but neither in cortex nor in microglial cells sorted from challenged animals. Cortical brain injury induced upregulation of several genes encoding for 
pro-inflammatory cytokines at P2 and P4 and defective myelination at P10. No genderrelated vulnerability to brain damage was observed in this model.

Transcriptomic analyses revealed that the low-dose IL1 $\beta$ treatment used in the model did not trigger substantial effects on gene expression of sorted microglial cells from P4 rat pups versus controls (Fig. 1C). In contrast, a synergistic effect of the double-hit (antenatal LPD plus postnatal IL1 $\beta$ ) was observed especially in up-regulated gene sets related to inflammation (Fig. 1C-1E). Gene Set Enrichment Analysis (GSEA) showed an enrichment of several "hallmark" gene sets involved in the inflammatory response, in line with the immunohistological results (Fig. 1F).

Then, transcriptomic data was studied for upregulated genes in response to a double hit insult using the network analysis tool Cytoscape (http://www.cytoscape.org/), after generating a network using String (http://string-db.org/). The network obtained, simplified by selecting "hub" genes known to be connected to several others, demonstrated a strongly enriched number of "edges" (gene-gene relations; 128 edges found while 43 were expected; p-value $<10^{-100}$ ). Within biological processes, activation of immune signaling appeared almost exclusive (Fig. 1F, Table 1). The network analysis was centered on IL $1 \beta$ that appeared as the major hub gene (Fig. 1G).

\section{Effect of carbetocin on microglial activation in vivo.}

We next tested the hypothesis that OXT insufficiency could be involved in the perinatal brain damage observed in the model. We used carbetocin, a long-lasting brain-permeable OXTR agonist (Dvorska et al., 1992) simultaneously with low-dose IL1ß on P1 and P2. Carbetocin treatment induced a significant reduction of $\mathrm{Iba} 1^{+}$microglial cell density within the developing white matter in LPD+IL1 $\beta$ P4 animals (Fig. 2A, 2B). Using qRT-PCR on cortex from P4 rat pups, carbetocin significantly prevented up-regulation of IL6, IL1 $\beta$, TNF $\alpha$ and iNOS, all markers of classical cytotoxic microglial activation, in animals subjected to a double-hit insult (Fig. 2C). Conversely, carbetocin did not change the gene expression of alternate activation markers including Arg1, IGF1, Mrc1 and Sphk1. Focusing on the effects of carbetocin at the 
transcriptional levels, microarray analysis revealed a $50 \%$ reduction in the number of genes up-regulated more than 1.5 fold (16 vs 32$)$ in sorted microglial cells from animals treated with carbetocin compared to untreated animals (Fig. 2D, 2E). Up-regulated genes network based on gene expression of the microglial cells isolated from animals treated by carbetocin included IL10, CXCL2, NOS2 and NCAM1 genes involved in the induction or regulation of brain inflammation (Fig. 2F). Interestingly, the main gene sets involved in the inflammatory which are up-regulated in the double hit model were systematically found to be downregulated by carbetocin treatment (Fig. 2G). Looking at the "TNF $\alpha$ signaling via NFKB cascade" gene set in more details, we isolated the subset of core genes composed of 57 genes that were up-regulated 1.41-fold in LPD+IL1 $1 \beta$ animals and down-regulated 0.81-fold by carbetocin treatment. The product of the inductions for each gene yielded an induction ratio of 1.14 , not significantly different from 1 (Fig. $2 \mathrm{H}$ ).

\section{Effect of carbetocin on FGR-associated microglial activation in vitro}

To further investigate the direct effect of carbetocin on microglial activation in vitro, we studied microglial cells sorted from P2 animals subjected to LPD and controls, with and without in vitro pro-inflammatory exposure to IL $1 \beta+I N F \gamma$. Forty-eight hours after sorting and plating, pure microglial cell cultures were stained using Iba1 (Fig. 3A). A marked increase in the concentrations of several pro-inflammatory cytokines was detected in the culture medium of sorted primary microglia from LPD-exposed animals (Fig. 3B). The exposure to LPD induced significant changes in microglial cell morphology with a reduced cell surface area, a reduced cell perimeter and increased cell circularity, all markers of microglial activation (Fig. 3C-3E). Pro-inflammatory challenge induced cell morphology changes towards amoeboid shape in control cells but not in LPD-derived cells that showed an activated profile already in basal condition. In both cell groups, carbetocin was able to significantly alleviate microglial activation (Fig. 3C, 3D). Gene expression of microglial activation markers were assessed in sorted primary microglial cultured cells from LPD brains and controls under basal conditions and after $\mathrm{IL} 1 \beta+\mathrm{INF} \gamma$ stimulation in the presence or absence of carbetocin alone or in 
combination with OXTR antagonist L-368-899 (Fig. 3F). A 4-fold increase in the expression of all cytotoxic markers was detected in microglial cells from LPD brain both under basal conditions and after stimulation. Carbetocin was able to partially prevent microglial overactivation in response to pro-inflammatory stimulus. L-368-899 significantly reversed this effect suggesting that the carbetocin effect on microglial activation in vitro was OXTRmediated.

\section{Effect of carbetocin on hydrocortisone-induced microglia activation in zebrafish embryos}

We further investigated the effect of carbetocin on microglia activation in vivo, using an established model of neuroinflammation induced by chronic hydrocortisone incubation of zebrafish larvae (Hartig, Zhu, King, \& Coffman, 2016), applied to the Tg[ApoE:eGFP] zebrafish transgenic line (Peri \& Nusslein-Volhard, 2008), which allows live imaging of microglial cells (Fig. 4A-4C).

First, zebrafish embryos exposed to $1.3 \mu \mathrm{M}$ hydrocortisone from $1 \mathrm{hpf}$ to 7 days postfertilization (dpf), displayed evidence of microglial activation including a 3- to 6.7-fold increased expression of the pro-inflammatory cytokines IL1 $\beta$, IL8 and TNFa (Fig. 4D) and a significant reduction in the number and length of microglia processes (Fig. 4E). Two-day treatment with $1 \mu \mathrm{M}$ carbetocin did not induce any effect on cytokine expression and cell shape in controls but markedly attenuated the effects of hydrocortisone, with microglial cells recovering elongated processes and a ramified morphology, similar to that seen in nontreated controls (Fig. 4D, 4E). The effects of hydrocortisone on microglia morphology were quantified using Imaris software (Bitplane Inc.) showing a significant increase of cell sphericity, marked decreases of their volume, surface area, and surface area/volume ratio, all effects reversed by carbetocin (Fig. 4F). We also performed in vivo time-lapse confocal imaging combined with image analysis and quantification to assess microglial cell dynamics using the Imaris software (Supplementary videos S1-S4). Hydrocortisone treatment induced significant increase in the mean speed of their processes and mean track displacement 
measurements (Fig. 4G, 4H). Carbetocin strongly reduced the effects of hydrocortisone, resulting in quantitative measurements similar to those determined in control embryos.

\section{Long-term impact of carbetocin on myelination, in vivo brain connectivity and}

\section{behavior}

We investigated whether carbetocin, by targeting neuroinflammation, could prevent brain damage and its long-term consequences in the present model of perinatal brain injury. Despite no detectable gross morphological damage, assessment of myelination at P10 revealed a significant decrease in the myelin content $\left(\mathrm{MBP}^{+}\right.$fibers) and $\mathrm{APC}^{+}$mature oligodendrocytes within the cingulate white matter and external capsule in animals subjected to a LPD+IL1 $\beta$ challenge (Fig. 5A, 5B). The total oligodendroglial population $\left(\mathrm{Olig}^{+}\right.$cells) was found to be unaffected suggesting a disruption of the oligodendroglial lineage.

Using functional ultrasound (fUS), computation of highly sensitive cerebral blood volume (CBV) maps related to underlying neuronal activity was recorded in animals at P28. Each brain imaging plane was co-registered with a rat brain atlas reference (Paxinos $\&$ Watson, $6^{\text {th }}$ Ed., 2007) to compute average ROIs-based CBV signals that exhibit various degrees of correlation (Fig. 6A, 6B). Pearson correlation coefficients between inter- and intrahemispheric couples of ROls were gathered into a matrix whose correlation levels and spatial patterns reflected a degree of cerebral connectivity that can be compared between groups (Fig. 6C). Inter-hemispheric somatosensory connectivity was significantly depressed in animals exposed to perinatal brain injury in the retrosplenial granular cortex (RSG), in a critical position between the hippocampal formation and the neocortex retrosplenial dysgranular cortex (RSD), medial and lateral parietal association cortex (LPtA, MPtA) and in most parts of the thalamic area (Fig. 6D). Carbetocin treatment prevented the loss of interhemispheric connectivity in most of areas. Intra-hemispheric connectivity was also found to be severely impaired (Fig. 6E). Again, carbetocin was associated with the significant prevention of functional disorders involving RSD and the parietal association cortex.

Finally, behavioral consequences of LPD+IL1 $\beta$ exposure and carbetocin treatment were 
assessed in 28-day animals for open-field (OF) and 2-month animals for Y-maze tests. Track records in the OF were divided into three different zones from center to periphery of the arena (Fig. 7A, 7B). Animals subjected to LPD+IL1 $1 \beta$ spent significantly more time in the periphery of the arena than did control animals. They traveled a longer distance in the intermediate zone between the periphery and the center and their velocity was higher in the center, findings suggesting anxiety-like behavior (Fig. 7B). Carbetocin treatment fully prevented these behavioral alterations. In the Y-maze test, distance traveled during the first 5 minutes of the habituation period was found to be significantly greater in animals subjected to the double-hit than in controls (Fig. 7C). Percentage of time spent in the novel arm during the retention task was significantly lower in LPD+IL1 $\beta$ animals, suggesting their incapacity to recognize novelty (Fig. 7D). These effects were consistently prevented by carbetocin treatment. 


\section{Discussion}

This study demonstrates that early postnatal activation of OXTR after birth is able to modulate microglial activity and is associated with a significant protection of the neonatal brain subjected to a pro-inflammatory challenge. Carbetocin reduced most of the effects, in particular microglial activation, observed in a double hit model of perinatal brain injury induced by gestational LPD and potentiated by postnatal injections of subliminal doses of IL1ß. The central anti-inflammatory effects of carbetocin have been shown in vivo in rat pups and reproduced both in vitro on stimulated sorted primary microglial cell cultures from rats subjected to LPD and in vivo in a zebrafish model of early-life neuroinflammation. These findings were associated with in vivo effects on myelination, and on long-term brain connectivity and behavior.

The present animal model was designed to be as relevant as possible considering the complexity of FGR in humans. Following birth, growth-restricted neonates are more prone to develop inflammatory-related damage resulting in cerebral palsy, cognitive and behavioral disorders (Miller, Huppi, \& Mallard, 2016). The preclinical model used in the present study was set up to replicate both FGR and these inflammatory-related events frequently observed in human neonates. Recent findings have suggested that growth-restricted rats already show an exacerbated neuro-inflammatory response associated with damages to the developing brain (Campbell et al., 2012; Rideau Batista Novais et al., 2016). In this vulnerable context, a subliminal inflammatory challenge had a synergistic deleterious effect on the brain in growthrestricted rat pups.

Like many other models of perinatal stress, our model was found to be associated with an early imbalance between the HPA axis and the OXT system, two hypothalamic systems of crucial importance during brain development: exposure to a series of unpredictable stresses during the final week of pregnancy (Lee et al., 2007), repeated restrain stress(Mairesse et 
al., 2015) or prenatal cocaine (Williams \& Johns, 2014) induced in the offspring an elevation of $\mathrm{CRH}$ production concomitantly with reduced OXT levels in the hypothalamus. The role of this imbalance in the developmental programing of neuroinflammation remains to be clarified. As a first hypothesis, the decreased OXT system activity associated with an increased HPA axis activity could result in an early excessive exposure to glucocorticoids that could, by epigenetic mechanisms, permanently decrease the expression of glucocorticoid receptors (GR) in the immune cells including microglial cells. As a result, this enduring loss of antiinflammatory effects of endogenous glucocorticoids could shift the immune response toward a pro-inflammatory phenotype later in life (Vanbesien-Mailliot et al., 2007).

Here we have demonstrated that the long-lasting OXTR agonist, carbetocin was able to block microglial overactivation associated with gestational LPD, not only in vivo but also directly in vitro. Similar anti-inflammatory effects of OXT have previously been reported in adults following the exposure of bacterial endotoxin (Clodi et al., 2008), or LPS in macrophages and endothelial cells (Szeto et al., 2008) and even in microglial cells (Yuan et al., 2016). The biological action of OTX is linked to the activation of OXTR, a selective seventransmembrane $\mathrm{G}_{\mathrm{q}} / \mathrm{G}_{\mathrm{i}}$-coupled receptor expressed both in astrocytes and in microglia(Karelina et al., 2011; Yuan et al., 2016), particularly in response to inflammation (Szeto et al., 2017). Indeed, exposure of microglia cells to inflammatory stimulus induced a time-dependent increase in OTXR expression suggesting that the sensitivity of microglia to OTX could be potentiated in response to an immune challenge.

The molecular basis of the neuroprotective action of OTX remains unclear and modulation of the downstream ERK/MAPK pathway in microglial cells has been reported in only one study(Yuan et al., 2016). Alternative pathways could also be involved including other molecular effectors of OTXR (e.g. NFKB, eEF2 eukaryotic elongation factor 2) and could be linked to the modulation of the expression of other neurotransmitter receptors on the microglial surface membrane (Liu, Leak, \& Hu, 2016). The gene expression profile corrected by carbetocin treatment concerns genes involved in many different stresses, including DNA 
damage and apoptosis (Gadd45a), angiogenesis and coagulation (Vegfa, F3), inflammation (Rel, RelB, NFKB, IL1 $\beta$ ). This concerted action could explain the various and sustained improvements observed in the treated animals.

Interestingly, our findings were not restricted to rodents, but were replicated in optically transparent zebrafish embryos, not only on cell morphology or gene regulation but also on the dynamics of microglial cell processes. Altogether, these data demonstrate an evolutionarily conserved anti-inflammatory function of OXT-OXTR, which targets the microglia and markedly alleviates the differentiation of these cells towards an activated cytotoxic profile.

Targeting neuroinflammation is critical in protecting the developing brain because both systemic and central inflammation play a role in the blockade of oligodendrocyte maturation leading to long-term myelination defects and finally cognitive defects in the neonate(Volpe, 2009). In neonates born after FGR, the levels of circulating cytokines were found to be significantly increased on days 7 and 14 compared with levels measured in neonates without FGR (Leviton et al., 2013; McElrath et al., 2013). This postnatal systemic pro-inflammatory state following FGR could, at least in part, be responsible for the brain insults and neurodevelopmental impairments detected in childhood in these individuals.

Microglia cells play a major role in the vulnerability of the immature brain to various challenges, mediating not only classic cytotoxicity but also alternative functions including repair, regeneration and immunosuppression, owing to their ability to acquire diverse activation states or phenotypes (Chhor et al., 2013). Their exacerbated activation may reverse their beneficial physiological properties, impairing neurogenesis and myelination and leading to neuronal and axonal death (Pierre et al., 2017). Some microglia functions have been shown to be required for myelination: an excessive microglial activation is usually associated with a reduction in oligodendrocyte progenitors, a maturational arrest of the oligodendroglial lineage and hypo-myelination (Favrais et al., 2011).

Although excessive microglial activation is linked to injury, microglial depletion is also associated with adverse effects in the developing brain (Faustino et al., 2011; Fernandez- 
Lopez et al., 2016). The colonization of the human brain by microglial cells during fetal life, between 12 and $24 \mathrm{GW}$, leads to clusters of activated microglia in the corpus callosum, the axonal crossroads and the periventricular white matter, all areas usually injured in neonates(Verney et al., 2012). FGR, which usually occurs at 18-24 GW and during the third trimester, could have a strong impact on the microglial cell lineage during this critical period. Some mouse models of genetic disruptions of microglial IL18 (Hedtjarn et al., 2002) or of galectin 3, interfering with the pro-inflammatory response(Burguillos et al., 2015), suggest that a finely tuned modulation of microglial activation through specific pathways (i.e. OXTR activation) rather than its global inhibition should be considered as an important therapeutic target to protect the developing brain.

Anti-inflammatory effects of carbetocin are probably responsible for the protection against the consequences of LPD+IL1 $\beta$ on myelination, seen not only at the histological level but also at the functional level as evidenced by functional ultrasound imaging (fUS) and behavioral testing. We have already reported the high sensitivity of fUS technology not only in rodents (Rideau Batista Novais et al., 2016) but also in human neonates(Demene et al., 2017). fUS offers a valuable combination of penetration and spatiotemporal resolution unique for translational studies and appears to be a promising novel brain imaging modality in the field of perinatal medicine (Demene et al., 2017). Here, long-term alterations in brain connectivity in response to the LPD+IL1 $\beta$ challenge and the beneficial effect of early carbetocin treatment were associated with changes in behavior in the open-field test and cognitive abilities in the Y-maze test. These results are in agreement with the microstructural changes in gray matter and the decreased connectivity previously reported in association with increased anxiety-like behavior and reduced attention and memory performance in a rabbit model of growthrestriction(Illa et al., 2013). Interestingly, altered patterns of brain connectivity have also been correlated with motor, cognitive and behavioral outcomes in human children born growthrestricted (Batalle et al., 2012). 
In addition to structural damages, neuroinflammation is a common feature in the development of many neuropsychiatric diseases including autistic spectrum disorders (ASD), depressive and psychotic syndromes, and Alzheimer disease. Most of these disorders, in the context of the Developmental Origins of Health and Disease (DOHaD) framework, may originate in the perinatal life through exposure to stress, trauma and/or inflammation, all of which able to program individuals for an enduring constitutive vulnerability to central inflammatory responses (Flinkkila, Keski-Rahkonen, Marttunen, \& Raevuori, 2016). Based on the present study, we speculate that the reduced OXT tonus provoked by LPD+IL1 $\beta$ exposure could be a starting point for a pro-inflammatory trajectory leading to increased vulnerability to develop future neuropsychiatric disorders, a frequent co-morbidity in infants born preterm or following FGR. Restoring central OXT tonus early in life could thus be beneficial to neurobehavioral outcome in these infants exposed to perinatal inflammation. Supporting this hypothesis, studies showed that the social behavior alterations observed in a mouse model of ASD are causally linked to the OXT system (Penagarikano et al., 2015).

In conclusion, this study shows that modulation of activated microglia by carbetocin, a longlasting brain permeant OXTR agonist, confers neuroprotection of the immature brain towards perinatal insult. These findings suggest a key role for the OXT system as a promising therapeutic pathway in preventing deleterious effects of perinatal stress associated with preterm birth or fetal growth restriction. 
Page 22 of 54 


\section{References}

Alkozei, A., McMahon, E., \& Lahav, A. (2014). Stress levels and depressive symptoms in NICU mothers in the early postpartum period. J Matern Fetal Neonatal Med, 27(17), 17381743.

Batalle, D., Eixarch, E., Figueras, F., Munoz-Moreno, E., Bargallo, N., Illa, M., . . Gratacos, E. (2012). Altered small-world topology of structural brain networks in infants with intrauterine growth restriction and its association with later neurodevelopmental outcome. Neuroimage, $60(2), 1352-1366$.

Burguillos, M. A., Svensson, M., Schulte, T., Boza-Serrano, A., Garcia-Quintanilla, A., Kavanagh, E., ... Deierborg, T. (2015). Microglia-Secreted Galectin-3 Acts as a Toll-like Receptor 4 Ligand and Contributes to Microglial Activation. Cell Rep.

Campbell, L. R., Pang, Y., Ojeda, N. B., Zheng, B., Rhodes, P. G., \& Alexander, B. T. (2012). Intracerebral lipopolysaccharide induces neuroinflammatory change and augmented brain injury in growth-restricted neonatal rats. Pediatr Res, 71(6), 645-652.

Chhor, V., Le Charpentier, T., Lebon, S., Ore, M. V., Celador, I. L., Josserand, J., . . Fleiss, B. (2013). Characterization of phenotype markers and neuronotoxic potential of polarised primary microglia in vitro. Brain Behav Immun, 32, 70-85.

Christensen, D., Van Naarden Braun, K., Doernberg, N. S., Maenner, M. J., Arneson, C. L., Durkin, M. S., . . Y Yeargin-Allsopp, M. (2014). Prevalence of cerebral palsy, co-occurring autism spectrum disorders, and motor functioning - Autism and Developmental Disabilities Monitoring Network, USA, 2008. Dev Med Child Neurol, 56(1), 59-65. 
Clodi, M., Vila, G., Geyeregger, R., Riedl, M., Stulnig, T. M., Struck, J., . . Luger, A. (2008). Oxytocin alleviates the neuroendocrine and cytokine response to bacterial endotoxin in healthy men. Am J Physiol Endocrinol Metab, 295(3), E686-691.

Dellu, F., Mayo, W., Cherkaoui, J., Le Moal, M., \& Simon, H. (1992). A two-trial memory task with automated recording: study in young and aged rats. Brain Res, 588(1), 132-139.

Demene, C., Baranger, J., Bernal, M., Delanoe, C., Auvin, S., Biran, V., . . Baud, O. (2017). Functional ultrasound imaging of brain activity in human newborns. Sci Trans/ Med, 9(411).

Dvorska, I., Brust, P., Hrbas, P., Ruhle, H. J., Barth, T., \& Ermisch, A. (1992). On the bloodbrain barrier to peptides: effects of immobilization stress on regional blood supply and accumulation of labelled peptides in the rat brain. Endocr Regul, 26(2), 77-82.

Faustino, J. V., Wang, X., Johnson, C. E., Klibanov, A., Derugin, N., Wendland, M. F., \& Vexler, Z. S. (2011). Microglial cells contribute to endogenous brain defenses after acute neonatal focal stroke. J Neurosci, 31(36), 12992-13001.

Favrais, G., van de Looij, Y., Fleiss, B., Ramanantsoa, N., Bonnin, P., Stoltenburg-Didinger, G., . . Gressens, P. (2011). Systemic inflammation disrupts the developmental program of white matter. Ann Neurol, 70(4), 550-565.

Feldman, R. (2015). Sensitive periods in human social development: New insights from research on oxytocin, synchrony, and high-risk parenting. Dev Psychopathol, 27(2), 369-395.

Fernandez-Lopez, D., Faustino, J., Klibanov, A. L., Derugin, N., Blanchard, E., Simon, F., . . . Vexler, Z. S. (2016). Microglial Cells Prevent Hemorrhage in Neonatal Focal Arterial Stroke. J Neurosci, 36(10), 2881-2893. 
Flinkkila, E., Keski-Rahkonen, A., Marttunen, M., \& Raevuori, A. (2016). Prenatal Inflammation, Infections and Mental Disorders. Psychopathology, 49(5), 317-333.

Guellec, I., Marret, S., Baud, O., Cambonie, G., Lapillonne, A., Roze, J. C., . . Ancel, P. Y. (2015). Intrauterine Growth Restriction, Head Size at Birth, and Outcome in Very Preterm Infants. J Pediatr, 167(5), 975-981 e972.

Hack, M., Flannery, D. J., Schluchter, M., Cartar, L., Borawski, E., \& Klein, N. (2002). Outcomes in young adulthood for very-low-birth-weight infants. N Engl J Med, 346(3), 149157.

Hagberg, H., Gressens, P., \& Mallard, C. (2012). Inflammation during fetal and neonatal life: implications for neurologic and neuropsychiatric disease in children and adults. Ann Neurol, 71(4), 444-457.

Hartig, E. I., Zhu, S., King, B. L., \& Coffman, J. A. (2016). Cortisol-treated zebrafish embryos develop into pro-inflammatory adults with aberrant immune gene regulation. Biol Open, 5(8), 1134-1141.

Hedtjarn, M., Leverin, A. L., Eriksson, K., Blomgren, K., Mallard, C., \& Hagberg, H. (2002). Interleukin-18 involvement in hypoxic-ischemic brain injury. J Neurosci, 22(14), 5910-5919.

Illa, M., Eixarch, E., Batalle, D., Arbat-Plana, A., Munoz-Moreno, E., Figueras, F., \& Gratacos, E. (2013). Long-term functional outcomes and correlation with regional brain connectivity by MRI diffusion tractography metrics in a near-term rabbit model of intrauterine growth restriction. PLoS One, 8(10), e76453. 
Jarvis, S., Glinianaia, S. V., Torrioli, M. G., Platt, M. J., Miceli, M., Jouk, P. S., . . . Surveillance of Cerebral Palsy in Europe collaboration of European Cerebral Palsy, R. (2003). Cerebral palsy and intrauterine growth in single births: European collaborative study. Lancet, 362(9390), 1106-1111.

Karelina, K., Stuller, K. A., Jarrett, B., Zhang, N., Wells, J., Norman, G. J., \& DeVries, A. C. (2011). Oxytocin mediates social neuroprotection after cerebral ischemia. Stroke, 42(12), 3606-3611.

Katz, J., Lee, A. C., Kozuki, N., Lawn, J. E., Cousens, S., Blencowe, H., . . Group, C. S.-f.G.-A.-P. B. W. (2013). Mortality risk in preterm and small-for-gestational-age infants in lowincome and middle-income countries: a pooled country analysis. Lancet, 382(9890), 417425.

Kimmel, C. B., Ballard, W. W., Kimmel, S. R., Ullmann, B., \& Schilling, T. F. (1995). Stages of embryonic development of the zebrafish. Dev Dyn, 203(3), 253-310.

Lee, P. R., Brady, D. L., Shapiro, R. A., Dorsa, D. M., \& Koenig, J. I. (2007). Prenatal stress generates deficits in rat social behavior: Reversal by oxytocin. Brain Res, 1156, 152-167.

Leviton, A., Dammann, O., \& Durum, S. K. (2005). The adaptive immune response in neonatal cerebral white matter damage. Ann Neurol, 58(6), 821-828.

Leviton, A., Fichorova, R. N., O'Shea, T. M., Kuban, K., Paneth, N., Dammann, O., . . . Investigators, E. S. (2013). Two-hit model of brain damage in the very preterm newborn: small for gestational age and postnatal systemic inflammation. Pediatr Res, 73(3), 362-370. 
Li, T., Wang, P., Wang, S. C., \& Wang, Y. F. (2016). Approaches Mediating Oxytocin Regulation of the Immune System. Front Immunol, 7, 693.

Liu, H., Leak, R. K., \& Hu, X. (2016). Neurotransmitter receptors on microglia. Stroke Vasc Neurol, 1(2), 52-58.

Mairesse, J., Gatta, E., Reynaert, M. L., Marrocco, J., Morley-Fletcher, S., Soichot, M., . . . Maccari, S. (2015). Activation of presynaptic oxytocin receptors enhances glutamate release in the ventral hippocampus of prenatally restraint stressed rats. Psychoneuroendocrinology, $62,36-46$.

McElrath, T. F., Allred, E. N., Van Marter, L., Fichorova, R. N., Leviton, A., \& Investigators, E. S. (2013). Perinatal systemic inflammatory responses of growth-restricted preterm newborns. Acta Paediatr, 102(10), e439-442.

Miller, S. L., Huppi, P. S., \& Mallard, C. (2016). The consequences of fetal growth restriction on brain structure and neurodevelopmental outcome. J Physiol, 594(4), 807-823.

Moisiadis, V. G., \& Matthews, S. G. (2014). Glucocorticoids and fetal programming part 2: Mechanisms. Nat Rev Endocrinol, 10(7), 403-411.

Penagarikano, O., Lazaro, M. T., Lu, X. H., Gordon, A., Dong, H., Lam, H. A., . . . Geschwind, D. H. (2015). Exogenous and evoked oxytocin restores social behavior in the Cntnap2 mouse model of autism. Sci Transl Med, 7(271), 271ra278.

Peri, F., \& Nusslein-Volhard, C. (2008). Live imaging of neuronal degradation by microglia reveals a role for v0-ATPase a1 in phagosomal fusion in vivo. Cell, 133(5), 916-927. 
Pierre, W. C., Smith, P. L., Londono, I., Chemtob, S., Mallard, C., \& Lodygensky, G. A. (2017). Neonatal microglia: The cornerstone of brain fate. Brain Behav Immun, 59, 333-345.

Rezaie, P., \& Dean, A. (2002). Periventricular leukomalacia, inflammation and white matter lesions within the developing nervous system. Neuropathology, 22(3), 106-132.

Rideau Batista Novais, A., Pham, H., Van de Looij, Y., Bernal, M., Mairesse, J., Zana-Taieb, E., . . Baud, O. (2016). Transcriptomic regulations in oligodendroglial and microglial cells related to brain damage following fetal growth restriction. Glia, 64(12), 2306-2320.

Romano, A., Tempesta, B., Micioni Di Bonaventura, M. V., \& Gaetani, S. (2015). From Autism to Eating Disorders and More: The Role of Oxytocin in Neuropsychiatric Disorders. Front Neurosci, 9, 497.

Subramanian, A., Tamayo, P., Mootha, V. K., Mukherjee, S., Ebert, B. L., Gillette, M. A., . . Mesirov, J. P. (2005). Gene set enrichment analysis: a knowledge-based approach for interpreting genome-wide expression profiles. Proc Natl Acad Sci U S A, 102(43), 1554515550.

Szeto, A., Nation, D. A., Mendez, A. J., Dominguez-Bendala, J., Brooks, L. G., Schneiderman, N., \& McCabe, P. M. (2008). Oxytocin attenuates NADPH-dependent superoxide activity and IL-6 secretion in macrophages and vascular cells. Am J Physiol Endocrinol Metab, 295(6), E1495-1501.

Szeto, A., Sun-Suslow, N., Mendez, A. J., Hernandez, R. I., Wagner, K. V., \& McCabe, P. M. (2017). Regulation of the macrophage oxytocin receptor in response to inflammation. Am J Physiol Endocrinol Metab, 312(3), E183-E189. 
Tyzio, R., Nardou, R., Ferrari, D. C., Tsintsadze, T., Shahrokhi, A., Eftekhari, S., . . Ben-Ari, Y. (2014). Oxytocin-mediated GABA inhibition during delivery attenuates autism pathogenesis in rodent offspring. Science, 343(6171), 675-679.

Vanbesien-Mailliot, C. C., Wolowczuk, I., Mairesse, J., Viltart, O., Delacre, M., Khalife, J., .. . Maccari, S. (2007). Prenatal stress has pro-inflammatory consequences on the immune system in adult rats. Psychoneuroendocrinology, 32(2), 114-124.

Verney, C., Pogledic, I., Biran, V., Adle-Biassette, H., Fallet-Bianco, C., \& Gressens, P. (2012). Microglial reaction in axonal crossroads is a hallmark of noncystic periventricular white matter injury in very preterm infants. J Neuropathol Exp Neurol, 71(3), 251-264.

Volpe, J. J. (2009). Brain injury in premature infants: a complex amalgam of destructive and developmental disturbances. Lancet Neurol, 8(1), 110-124.

Williams, S. K., \& Johns, J. M. (2014). Prenatal and gestational cocaine exposure: Effects on the oxytocin system and social behavior with implications for addiction. Pharmacol Biochem Behav, 119, 10-21.

Yuan, L., Liu, S., Bai, X., Gao, Y., Liu, G., Wang, X., . . Wang, Z. (2016). Oxytocin inhibits lipopolysaccharide-induced inflammation in microglial cells and attenuates microglial activation in lipopolysaccharide-treated mice. J Neuroinflammation, 13(1), 77.

Zana-Taieb, E., Pham, H., Franco-Montoya, M. L., Jacques, S., Letourneur, F., Baud, O., . . . Vaiman, D. (2015). Impaired alveolarization and intra-uterine growth restriction in rats: a postnatal genome-wide analysis. J Pathol, 235(3), 420-430. 


\section{Figure legends}

Figure 1: The double-hit rat model associating gestational low protein diet with postnatal inflammatory challenge.

A. Pups from isocaloric low protein diet (LPD, 9\% protein) and normal diet (Ctl, 22\% protein) fed mothers were injected i.p. at postnatal $(P)$ days 1 and 2 twice a day with IL $1 \beta$. Brain were then analyzed for mRNA transcription and protein expression directly or after microglia magnetic cell sorting. B. Consequences of the LPD treatment on the hypothalamic HPA and oxytocin systems mRNA expression at P1, and of LPD+IL1 $\beta$ treatment on the cortical mRNA at P2 and P4 (open circle) and on cortical protein expression at P4 and P10 (full circle). Data are means \pm SEM. All data were found significant and two-tailed unpaired t-test was used for comparisons (See Supplementary Table 1 for detailed numbers, t- and p-values). C, D. Arraymining analysis performed on sorted microglial cells at P4, showing a synergistic effect of LPD exposure and IL1 $\beta$ treatments ( $N=3$ sample per group). PC denotes Pearson Correlation (Meta-gene vs experimental group). E. Clustering focused on the comparison between microglial transcripts from LPD+IL1 $\beta$ and controls. F. GSEA analysis of the differential hallmarks of up-regulated genes in the comparison LPD+IL1 $1 \beta$ vs Controls. Significantly enriched gene clusters linked to inflammatory responses appeared in the upregulated genes. G. Up-regulated genes network on LPD and IL1 $\beta$ treatment. The purple color is more intense for the most abundant transcripts.

Figure 2: Central anti-inflammatory action of early postnatal carbetocin treatment in vivo.

A. Representative photomicrographs of $\mathrm{Iba}^{+}$cells (red) within cortical white matter of rat pups at P4 in the 4 experimental groups. Bars $=100 \mu \mathrm{m}$; LV: lateral ventricle. B. Carbetocin restores the number of $\mathrm{Iba} 1^{+}$ameboid cells per slice within in the white matter of LPD+IL1 $\beta$ animals. C. mRNA cortical expression of classical cytotoxic and alternate immunomodulatory proteins assessed at P1-P2 in in the 4 experimental groups. All comparisons in B and C 
were performed using one-way ANOVA followed by Newman-Keuls multiple comparison tests when appropriate. * and $\$$ is respect to control and LPD+IL1 $\beta$ respectively. Data are means \pm SEM. (See Supplementary Table 1 for detailed numbers, F- and p-values). D. Microarray analysis of microglia sorted cells reveals a clear clustering in gene expression between LPD+IL1 $\beta$ and LPD+IL1 $\beta+$ carbetocin ( $N=3$ per group). E. Venn diagram for up- and down-regulated genes in microglia from LPD+IL1 $\beta$ and LPD+IL1 $\beta+$ carbetocin respect to control. F. Up- and down-regulated genes network in LPD+IL1 $\beta$ with carbetocin treatment. G. GSEA analysis revealed that differential hallmarks gene sets of up-regulated genes by LPD+IL1 $\beta$ challenge, are systematically enriched in down regulated genes by carbetocin treatment. H. Example of gene sets up-regulated by LPD+IL1 $\beta$ treatment, and corrected by carbetocin treatment $(\mathrm{TNF} \alpha$ signaling via $\mathrm{NF} \kappa \mathrm{B})$. Gene expression ratios of core-induced genes were collected. In samples from carbetocin treated-animals, 57 genes of the core were down-regulated. The global outcome tends to bring back the genes to a ratio of 1 .

\section{Figure 3: In vitro effects of carbetocin and OXTR antagonist in primary microglial} cultured cells sorted from control and LPD brains with and without pro-inflammatory stimulation.

A. Representative photomicrographs of primary culture of microglial cells sorted from control and LPD brains at P2. Microglial cells were stained with Iba1 in basal condition, after proinflammatory stimulation (IL1 $\beta+$ INFY) in presence or not of $1 \mu \mathrm{M}$ carbetocin. Bar= $50 \mu \mathrm{m}$.

B. Multiplex assay for cytokine concentration measurements in the culture medium of primary microglia sorted from LPD-exposed and control animals. Two-tailed unpaired t-test was used for comparisons normalized to controls. ${ }^{* *}: p<0.01,{ }^{*}: p<0.05$. Data are means \pm SEM.

C. Microglial cell morphological changes induced by IL1 $\beta+$ INFY stimulation in presence or not of carbetocin in control and LPD groups considering cells area, cells perimeter and cells circularity. D. Mean cells area, for each condition, in 3 category of cells area with limit of size based on a control microglia in basal condition divided in 3 equal sub-groups. E. Distribution of cells number (in percent) for each of the 3 cell size groups for each condition. F. Gene 
expression of microglia phenotypic markers in primary microglial cultured cells sorted from control and LPD brains in basal condition and after IL1 $\beta+$ INFY stimulation in presence or not of carbetocin alone or in combination with the OXTR antagonist (L-368-899). IL6, TNFa, and iNOS mRNA (two-way ANOVA, $\mathrm{P}<0.001$ for all). Comparisons were performed using twoway ANOVA followed by Newman-Keuls multiple comparison tests; *, is respect to basal condition in either Ctl or LPD groups, \$ is respect to IL1 $\beta+$ INFY in either CtI or LPD groups, \# is respect to same condition in LPD compared to the control group, $\S$ is respect to L-368-899 compared to carbetocin effect. Data are means \pm SEM. (See Supplementary Table 1 for detailed numbers, t-, F- and p-values).

\section{Figure 4: Carbetocin effect on cortisol-induced microglia activation in zebrafish.}

A. Experimental set-up and drug exposure to dechorionated one day-old embryos. B. Live imaging of microglial cells in $8 \mathrm{dpf} \mathrm{Tg}[\mathrm{Apo}-\mathrm{E}-\mathrm{GFP}]$ embryos, in which microglial cells display an intense green fluorescent labelling used to follow their morphological changes and dynamic behavior in vivo. Anterior is on the right. C. Schematic drawing of the optic tectum, region of interest imaged in this study (red square). D. Carbetocin markedly decreases expression of cortisone-induced pro-inflammatory cytokines IL1 $\beta$, TNFa, and IL8. E. Carbetocin fully alleviates cortisol-induced shape changes of microglial cells. Scale bars: $50 \mu \mathrm{m}$. Lower panel depicts representative 3D Imaris software-reconstruction (Bitplane Inc.)

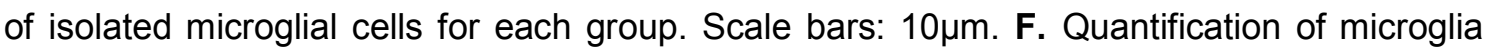
cell shape changes in response to the different drugs. Microglial cells of embryos exposed to hydrocortisone showed highly significant morphological changes, fully prevented by carbetocin. Carbetocin alone in control embryos have no detectable effect. G, H. Quantification of microglia processes dynamics (process track displacement and process speed) and performed using the Imaris software (Bitplane Inc.). See also supplementary Movies S1 to S4 that show the dynamic behavior of microglial processes. All comparisons were performed using one-way ANOVA followed by Newman-Keuls multiple comparison 
tests; ${ }^{* * *}$ and $\$ \$ \$(p<0.001)$ is respect to control and to hydrocortisone groups, respectively. Data are means \pm SEM. (See Supplementary Table 1 for detailed numbers, F- and p-values).

\section{Figure 5: Consequences of LPD+IL1 $\beta$ and carbetocin treatment on myelination.}

A. Representative photomicrographs of MBP immuno-reactivity assessment in the cingular and lateral white matter (CWM and LWM, respectively) in P10 animals. B. Quantification of MBP, APC and Olig2 immuno-reactivity in response to LPD+IL1 $\beta$ challenge and carbetocin treatment. Comparisons were performed using one-way ANOVA followed by Newman-Keuls multiple comparison tests when appropriate. ${ }^{*}$ and $\$$ is respect to control and LPD+IL1 $\beta$ respectively. Data are means \pm SEM. (See Supplementary Table 1 for detailed numbers, Fand p-values).

Figure 6: Consequences of LPD+IL1 $\beta$ and carbetocin treatment on myelination and functional intrinsic connectivity of the brain.

A. fUS imaging consists in the 300 repetitions of UfD image acquired every 2 s, resulting in 10 minutes of resting state imaging data performed two times consecutively for each animal. Intensity in one pixel of a UfD image is proportional to the local blood volume. These images were registered with a functional rat brain atlas for further regions of interest (ROIs) based subdivision. B. Based on this registration $10 \mathrm{RO}$ s were delineated on each side, resulting in a total of 20 ROls overall. In each of these regions the UfD signal was spatially averaged and temporally normalized to calculate Pearson correlation coefficient between every couple of signals. In this example, RSD signal is strongly similar on the left and right side (blue and purple signals), resulting in a high correlation coefficient $(0.87)$, whereas correlation is quite weak between left RSD and left ventral thalamus (blue and pink signals)(corr $=0.24$ ), this being interpreted as a low connectivity at that moment between those 2 cerebral structures. C. All these correlation coefficients were gathered into a matrix whose levels and spatial patterns reflect a degree of cerebral connectivity that can be compared between groups. This matrix is symmetrical, and one half is displayed as color for qualitative visual inspection and 
the other half is displayed as numerical values. The coefficients framed in white correspond to the so-called inter-hemispheric connectivity and the coefficients framed in blue correspond to the so-called intra-hemispheric connectivity (that can therefore be assessed on both left and right side).

D. Average functional connectivity map in the control and LPD+IL1 $\beta$ animals treated or not with carbetocin. Pearson correlation coefficients are indicated for the right and left hemisphere in the cortex (RSG, retrosplenial granular cortex; RSD, retrosplenial dysgranular cortex; MPtA, medial parietal association cortex; LPtA, lateral parietal association cortex), in the hippocampus (Hippo), in the dorsal, ventral and medial thalamic area (Thal D, Thal $V$ and Thal $M$, respectively) and in medial and lateral hypothalamic area (Hypot $M$ and Hypot $L$, respectively). E, F. Loss of inter-(E) and Intra-(F) hemispheric functional intrinsic connectivity in LPD+IL1 $\beta$ animals and correction by early carbetocin treatment. For statistical analyses, matrix Pearson coefficients were transformed using a Fisher transformation. Comparisons were performed using one-way ANOVA followed by Newman-Keuls multiple comparison tests; * and $\$$ is respect to control and LPD+IL1 $\beta$ respectively. Data are means \pm SEM. (See Supplementary Table 1 for detailed numbers, F- and p-values).

Figure 7: Behavioral consequences of LPD+IL1 $\beta$ and carbetocin treatment in juvenile and adult animals.

A. Representative track records in the open field (OF) test performed in the 4 experimental groups in 28-days old animals. B. Subdivision of the open field area in three complementary zones defines as periphery (Periph), intermediate (Inter) and center. All comparisons were performed using two-way ANOVA for repeated measures, followed by Bonferroni multiple comparison tests when appropriate, ${ }^{*}$ is respect to control, $\$$ respect to LPD+IL1 $\beta$. Data are means \pm SEM. (See Supplementary Table 1 for detailed numbers, F- and p-values). C, D. Behavior during the acquisition and the retention tasks of the Y-maze performed in the 4 experimental groups in 2 months old animals. Distance traveled during the 5 first minutes of the 15 minutes of habituation period during which only two arms of the Y-maze are available 
(C). Percentage of time spent in the novel arm during the retention task of the Y-maze, 3 hours after the acquisition (D). Comparisons were performed using one-way ANOVA followed by Newman-Keuls multiple comparison tests; * and $\$$ is respect to control and LPD+IL1 $\beta$ respectively. Data are means \pm SEM. (See Supplementary Table 1 for detailed numbers, $\mathrm{F}$ - and $\mathrm{p}$-values).

Table 1 : Functional network enrichment based on sorted microglia cells transcript analysis in LPD+IL1 $1 \beta$ exposed animals compared to controls. Networks which have significantly more interactions than expected are listed as biological processes, cellular components and KEGG pathways. 


\section{Supplementary materials legends}

\section{Supplementary Table 1:}

Detailed numbers, F- and p-values for each Figure.

\section{Supplementary video S1-S4:}

Movies of microglial cells from Tg[ApoE:GFP] embryos incubated in E3 medium alone (S1) or treated with carbetocin $(1 \mu \mathrm{M}, \mathbf{S 2})$ or hydrocortisone $(1.3 \mu \mathrm{M}, \mathbf{S 3})$ alone or in combination (S4), showing the dynamic behaviour of microglia and their filopodes. 
A
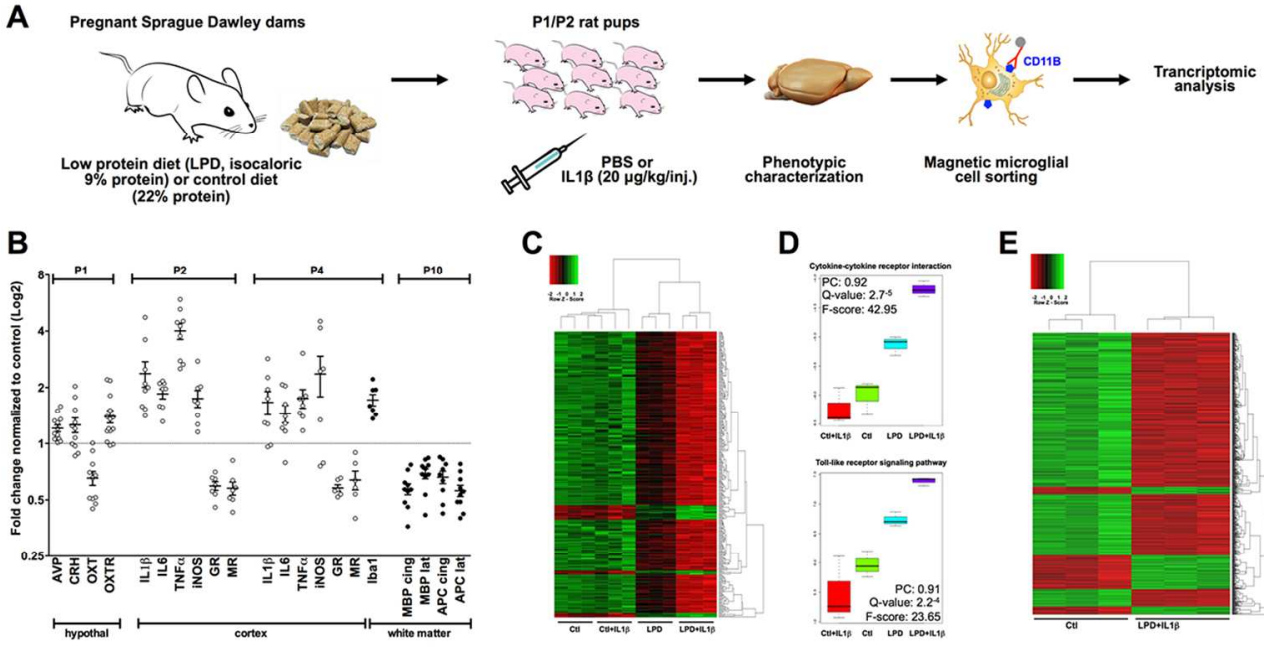

C

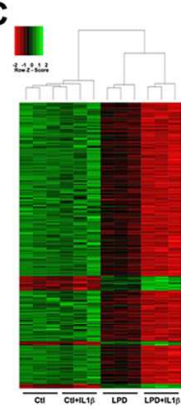

D

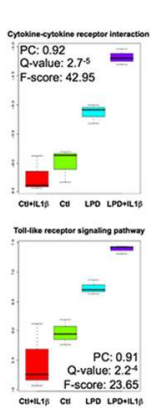

E

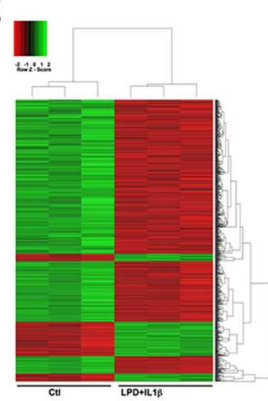

$\mathbf{F}$

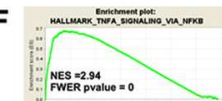

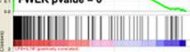

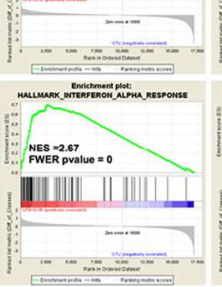

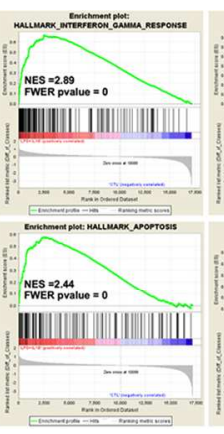

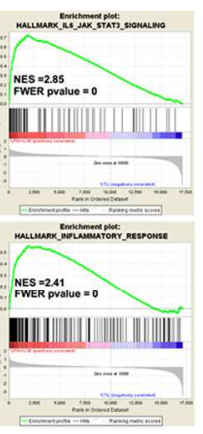

G

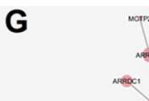

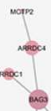

Genes overexpressed $>1.5$ fold in LPD+LL $1 \beta$

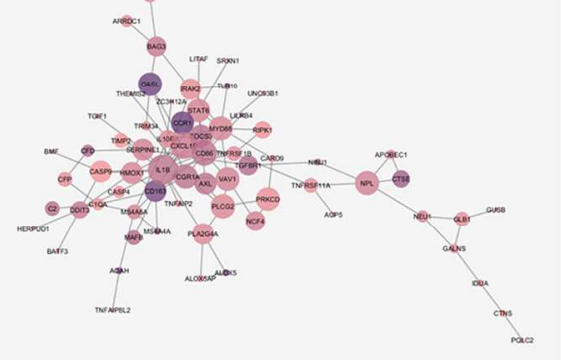

Figure 1: The double-hit rat model associating gestational low protein diet with postnatal inflammatory challenge.

A. Pups from isocaloric low protein diet (LPD, 9\% protein) and normal diet (CtI, 22\% protein) fed mothers were injected i.p. at postnatal (P) days 1 and 2 twice a day with IL1 $\beta$. Brain were then analyzed for mRNA transcription and protein expression directly or after microglia magnetic cell sorting. $B$. Consequences of the LPD treatment on the hypothalamic HPA and oxytocin systems mRNA expression at P1, and of LPD+IL1 $\beta$ treatment on the cortical mRNA at P2 and P4 (open circle) and on cortical protein expression at P4 and P10 (full circle). Data are means \pm SEM. All data were found significant and two-tailed unpaired t-test was used for comparisons (See Supplementary Table 1 for detailed numbers, t- and p-values). C, D. Arraymining analysis performed on sorted microglial cells at P4, showing a synergistic effect of LPD exposure and IL1 $\beta$ treatments ( $\mathrm{N}=3$ sample per group). PC denotes Pearson Correlation (Meta-gene vs experimental group). E. Clustering focused on the comparison between microglial transcripts from LPD+IL1 $\beta$ and controls. F. GSEA analysis of the differential hallmarks of up-regulated genes in the comparison LPD+IL1 $\beta$ vs Controls.

Significantly enriched gene clusters linked to inflammatory responses appeared in the up-regulated genes. G. Up-regulated genes network on LPD and IL1 $\beta$ treatment. The purple color is more intense for the most abundant transcripts. 
$\mathbf{A}$
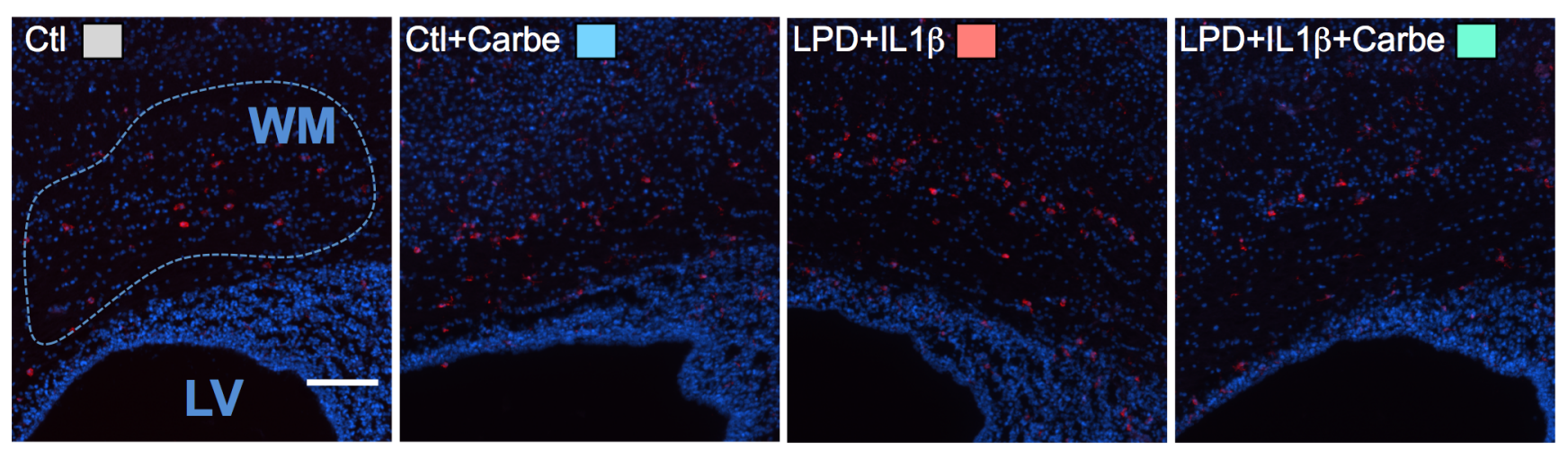

B

Page 38 of 54

C

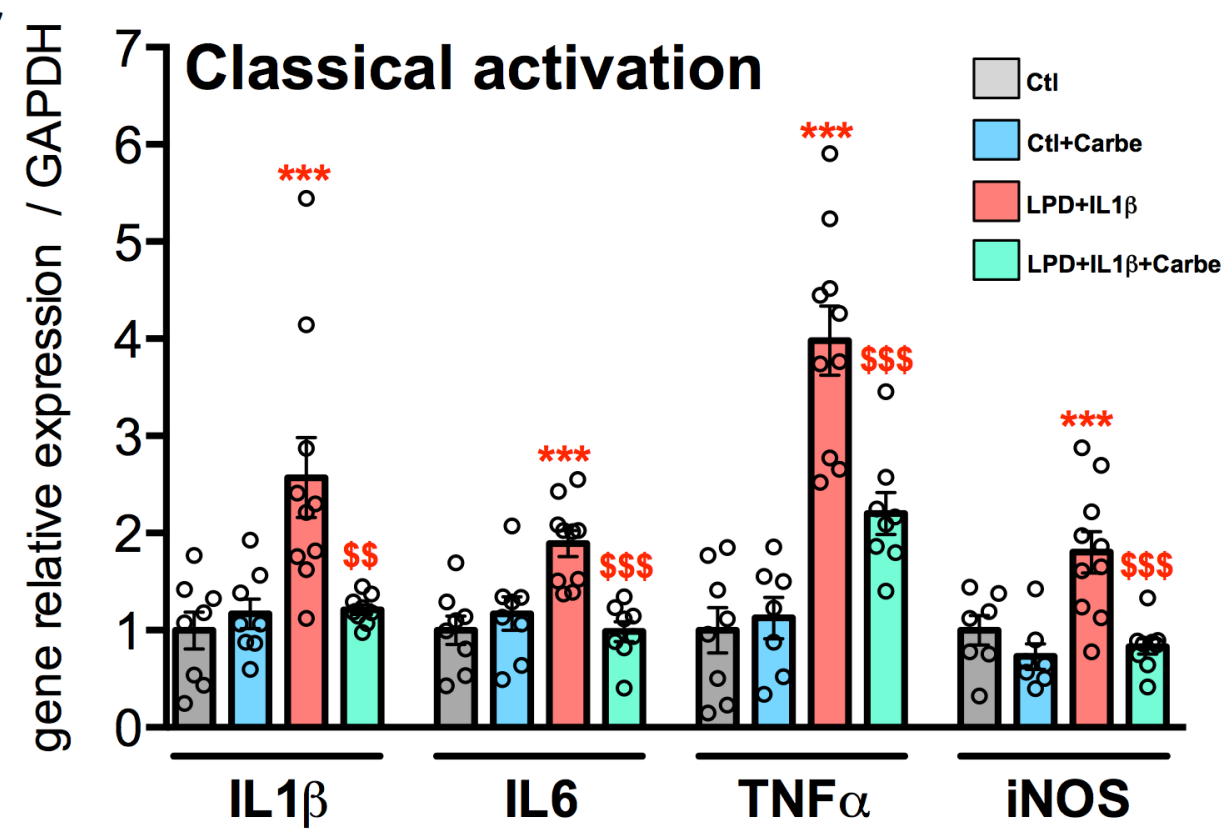

D

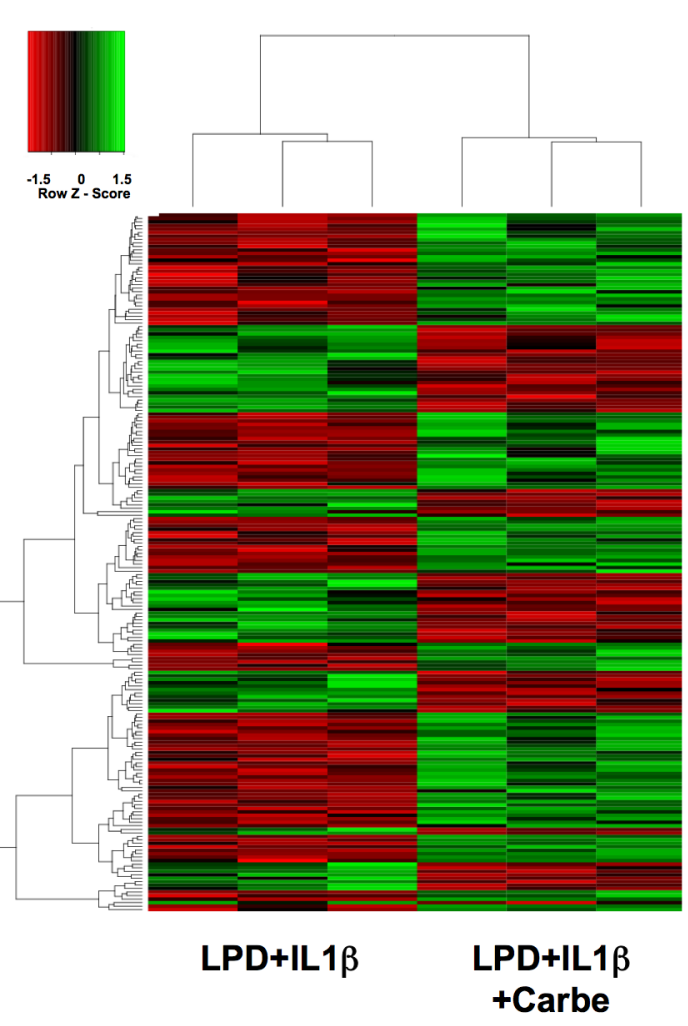

$\mathbf{F}$
E

UP

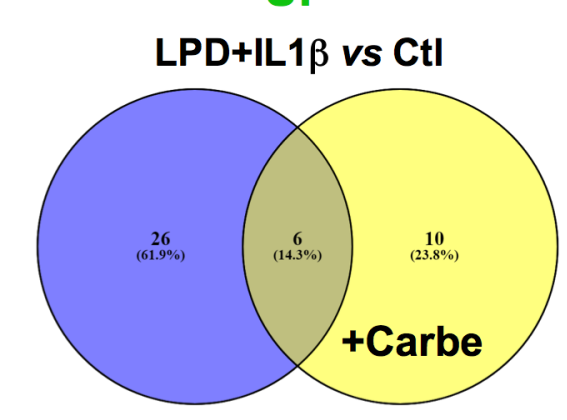

DOWN

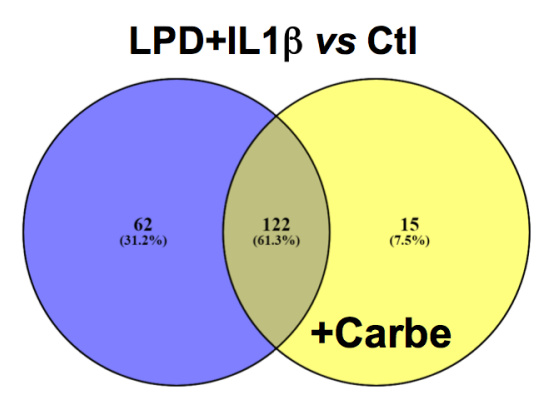

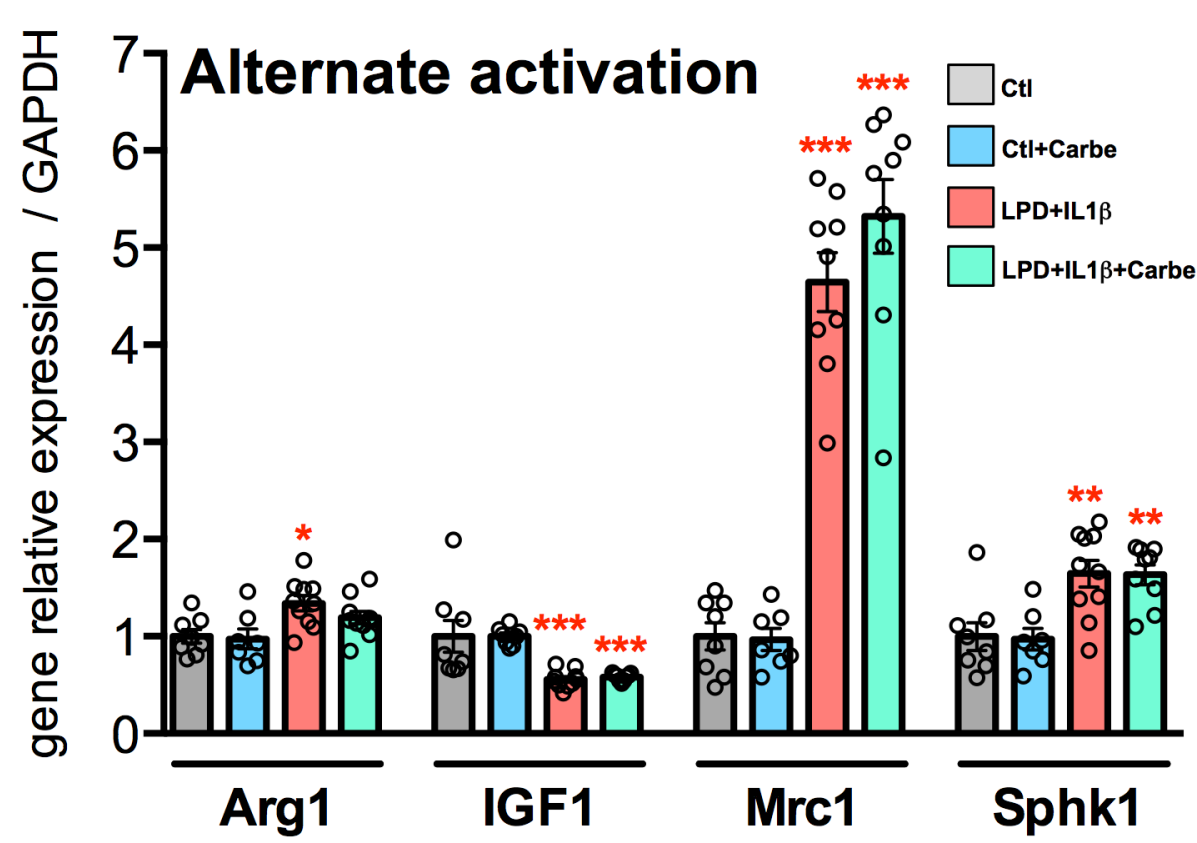

G
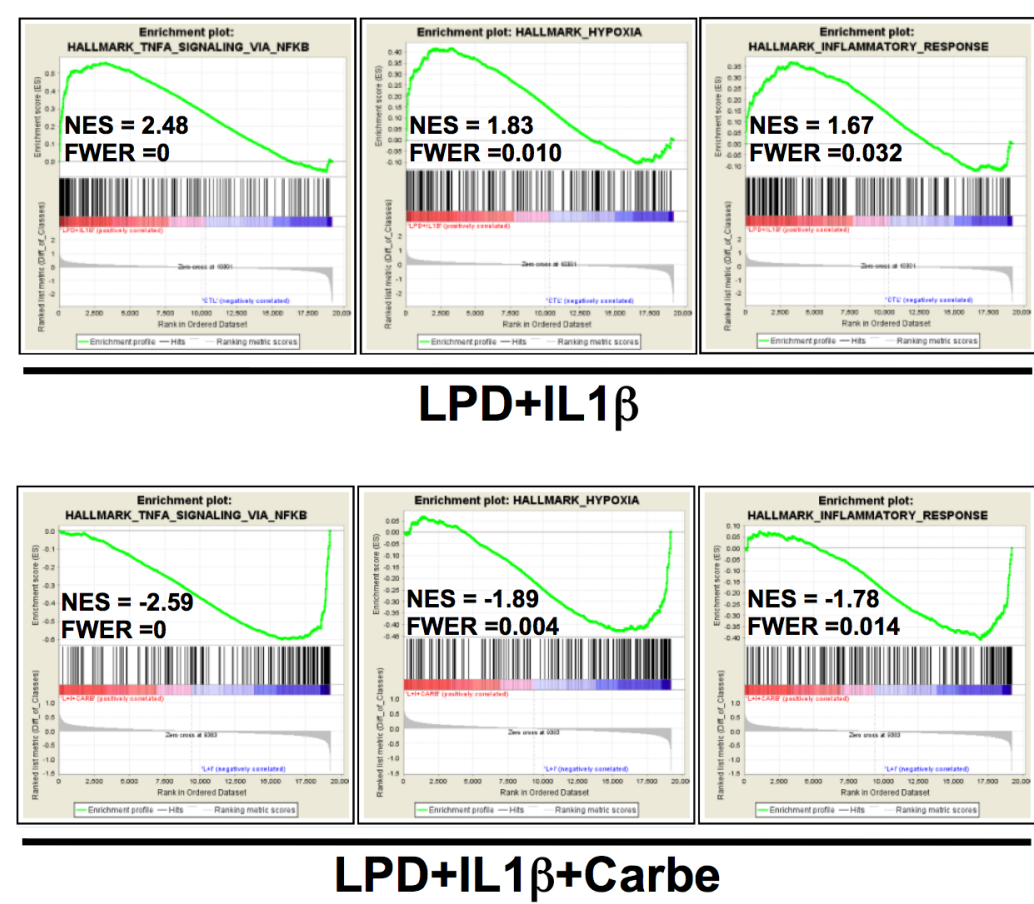

H

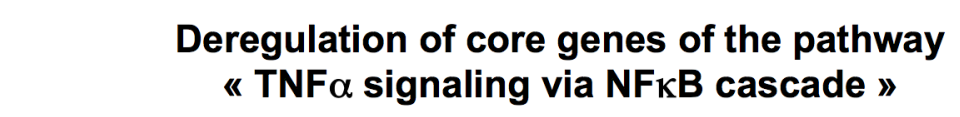

DOWN
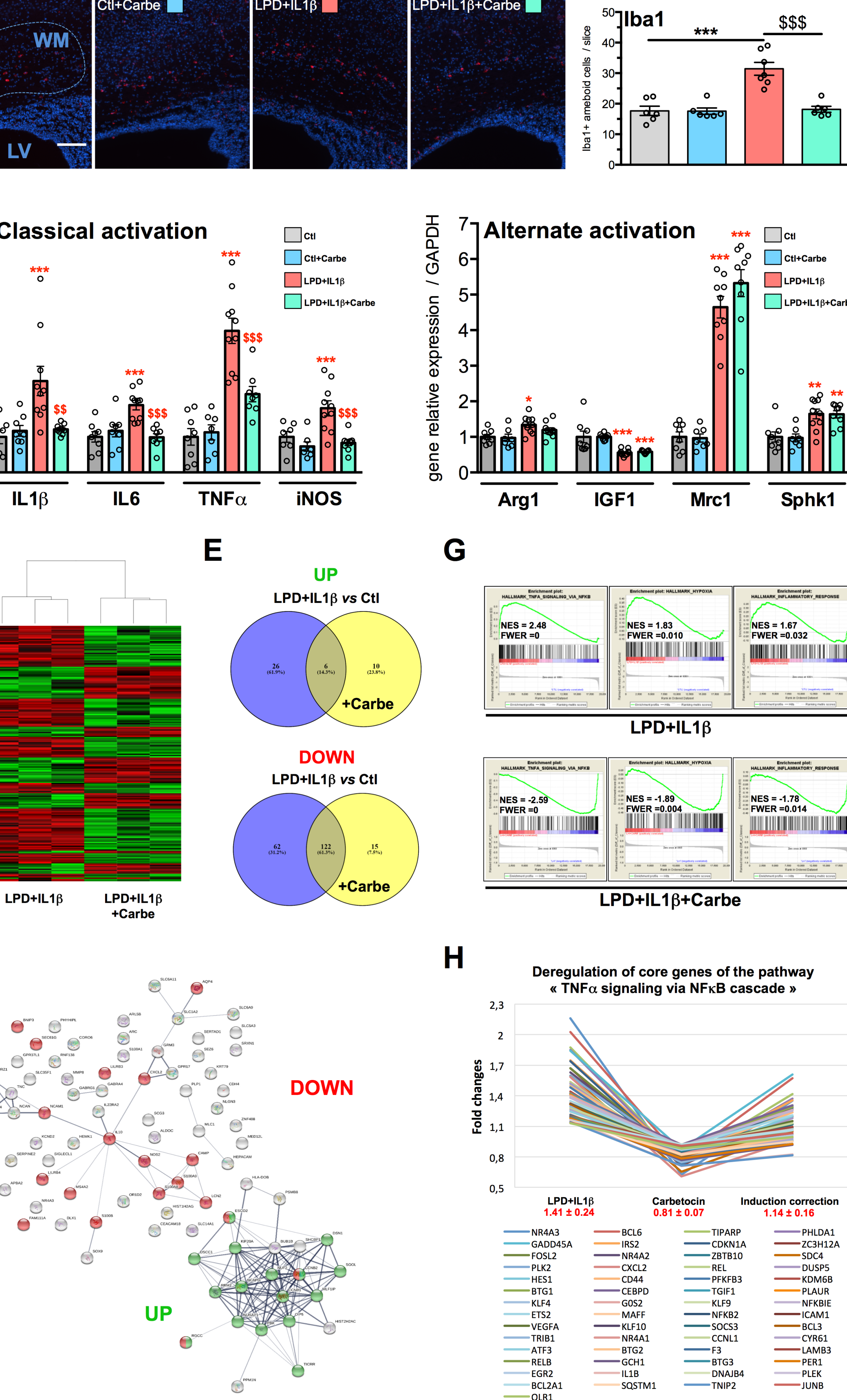

LPD+IL1 $\beta+$ Carbe " TNF $\alpha$ signaling via NFKB cascade " 
A

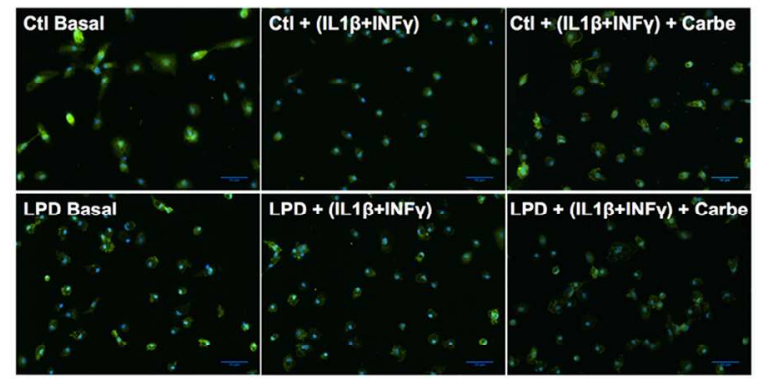

C
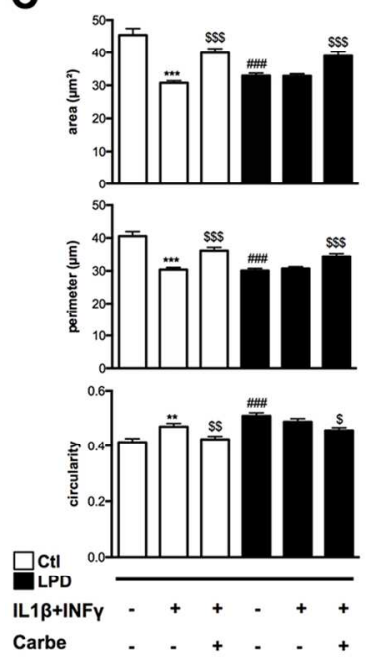

$\mathbf{E}$
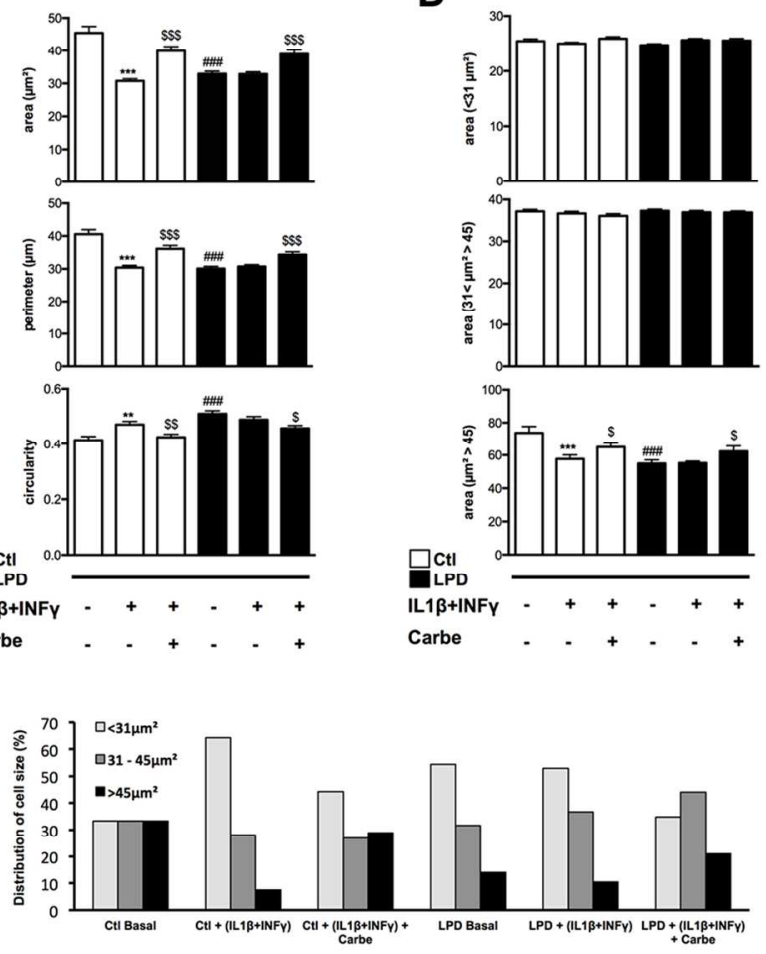

B

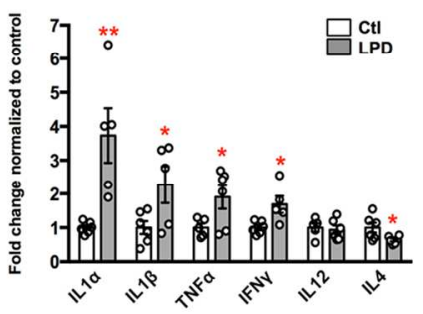

$\mathbf{F}$
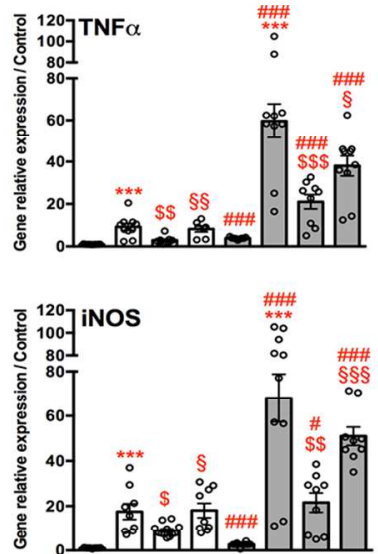

LLA1+1FNY Carbe
L-368-899

Figure 3: In vitro effects of carbetocin and OXTR antagonist in primary microglial cultured cells sorted from control and LPD brains with and without pro-inflammatory stimulation.

A. Representative photomicrographs of primary culture of microglial cells sorted from control and LPD brains at P2. Microglial cells were stained with Iba1 in basal condition, after pro-inflammatory stimulation (IL1 $\beta+$ INFY) in presence or not of $1 \mu \mathrm{M}$ carbetocin. Bar $=50 \mu \mathrm{m}$.

B. Multiplex assay for cytokine concentration measurements in the culture medium of primary microglia sorted from LPD-exposed and control animals. Two-tailed unpaired t-test was used for comparisons normalized to controls. $* *: p<0.01, *: p<0.05$. Data are means \pm SEM.

C. Microglial cell morphological changes induced by IL1 $\beta+I N F Y$ stimulation in presence or not of carbetocin in control and LPD groups considering cells area, cells perimeter and cells circularity. D. Mean cells area, for each condition, in 3 category of cells area with limit of size based on a control microglia in basal condition divided in 3 equal sub-groups. E. Distribution of cells number (in percent) for each of the 3 cell size groups for each condition. F. Gene expression of microglia phenotypic markers in primary microglial cultured cells sorted from control and LPD brains in basal condition and after IL1 $\beta+$ INFY stimulation in presence or not of carbetocin alone or in combination with the OXTR antagonist (L-368-899). IL6, TNFa, and iNOS mRNA (twoway ANOVA, $\mathrm{P}<0.001$ for all). Comparisons were performed using two-way ANOVA followed by NewmanKeuls multiple comparison tests; ${ }^{*}$, is respect to basal condition in either CtI or LPD groups, $\$$ is respect to 
IL1 $\beta+$ INFY in either CtI or LPD groups, \# is respect to same condition in LPD compared to the control group, $\S$ is respect to L-368-899 compared to carbetocin effect. Data are means \pm SEM. (See Supplementary Table 1 for detailed numbers, t-, F- and p-values). 
B
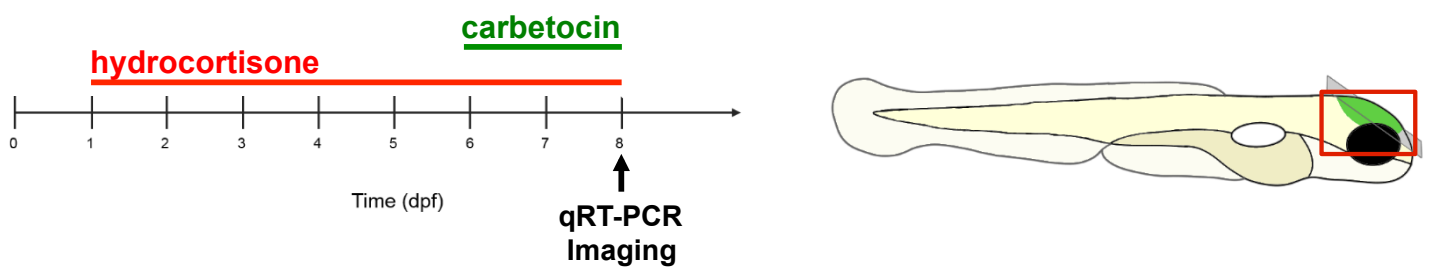

D $\square \mathrm{ctl} \quad \square$ ctl + Carbe $\square$ Hydrocortisone $\square$ Hydrocortisone + Carbe

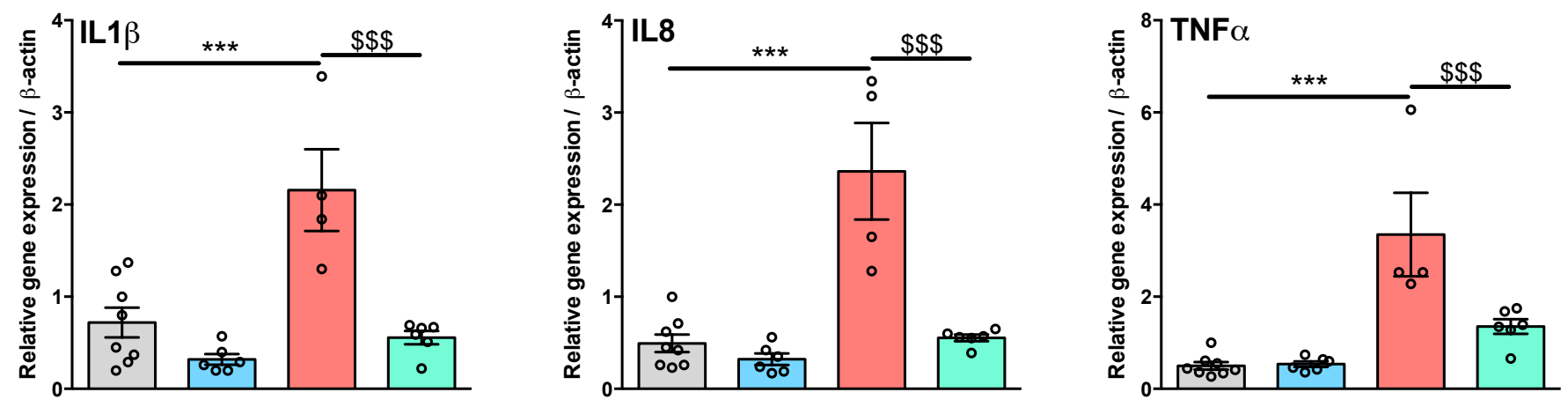

E
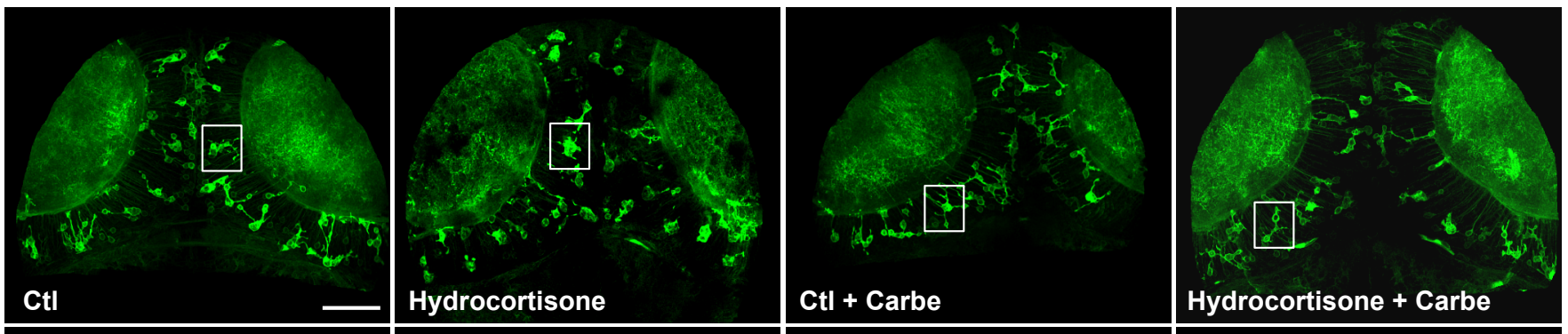

Ctl + Carbe
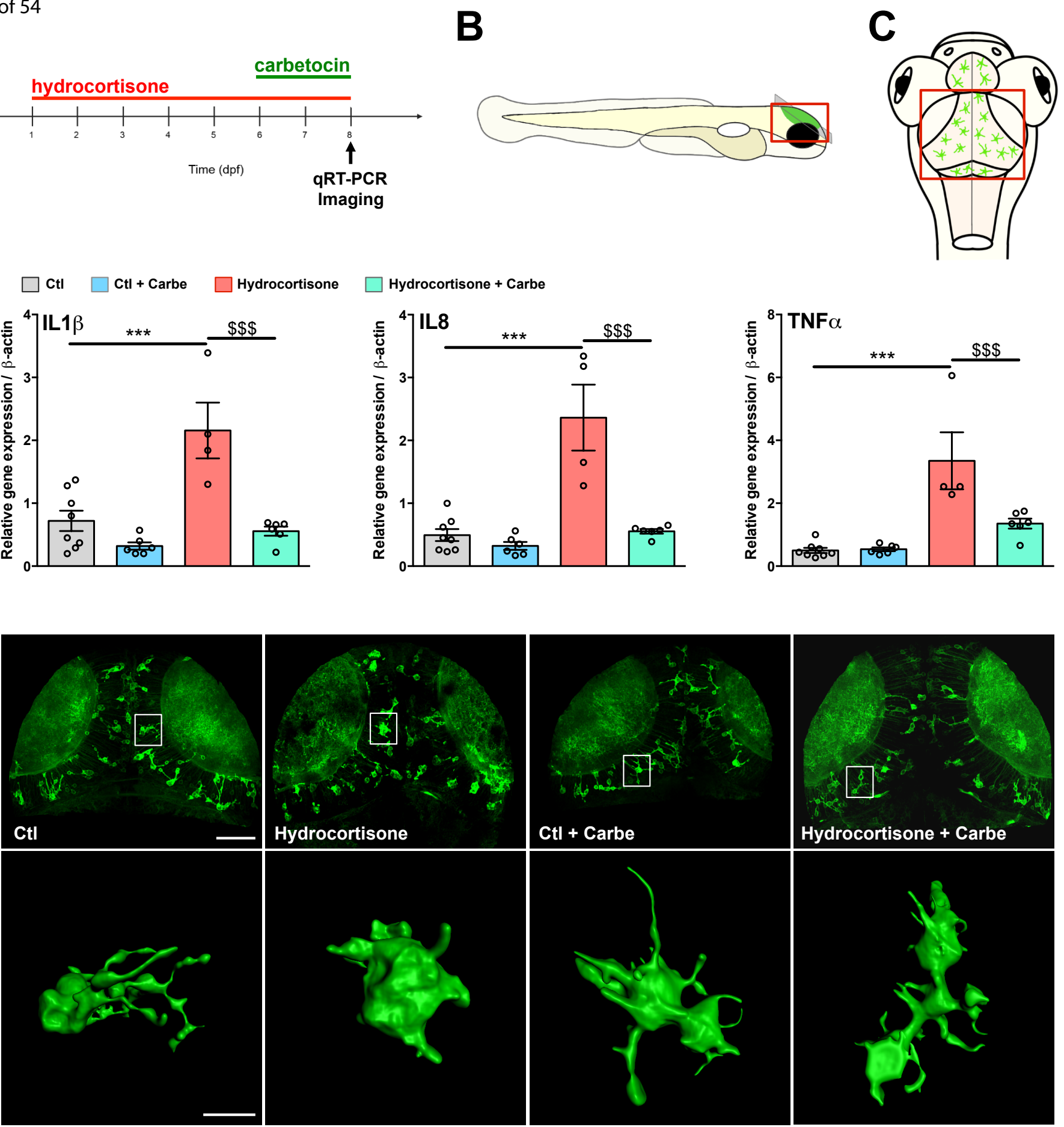

F
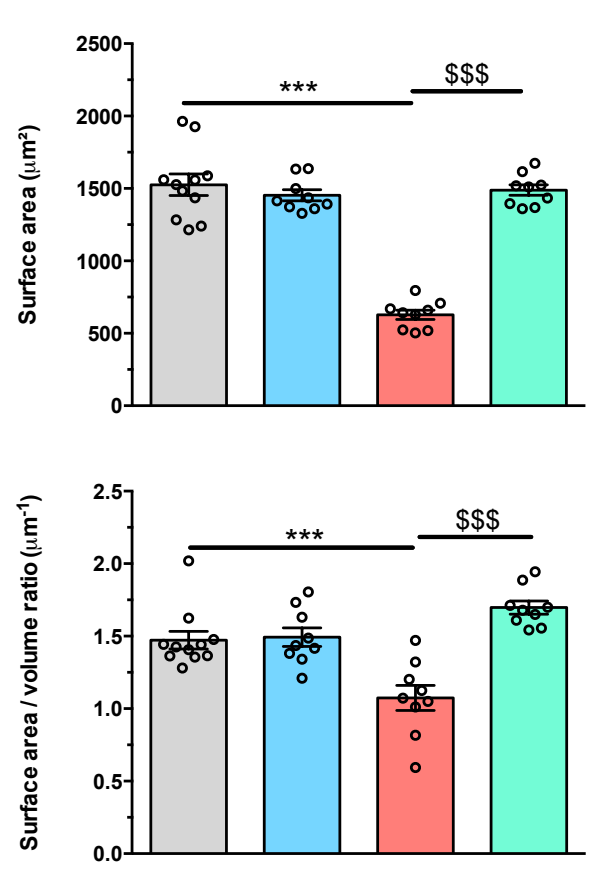

G
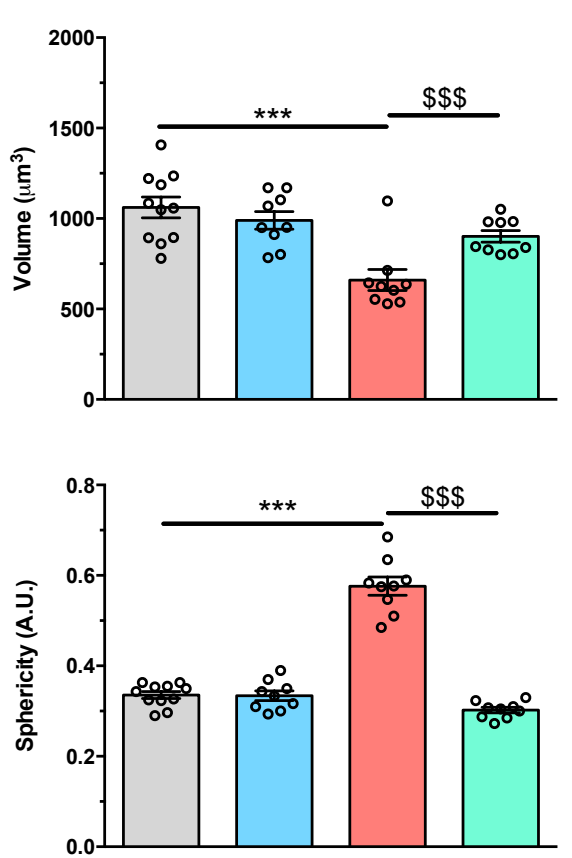

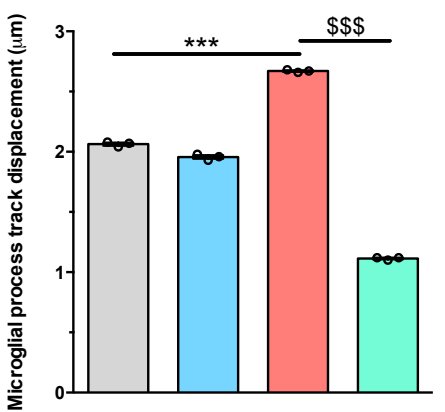

H

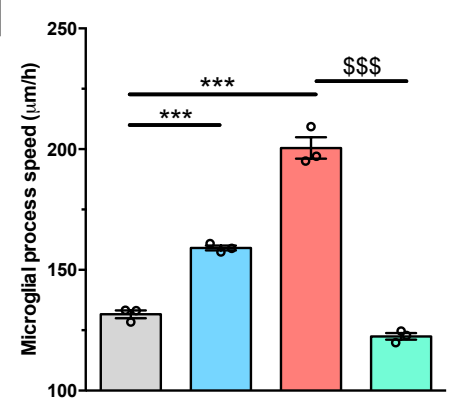


A

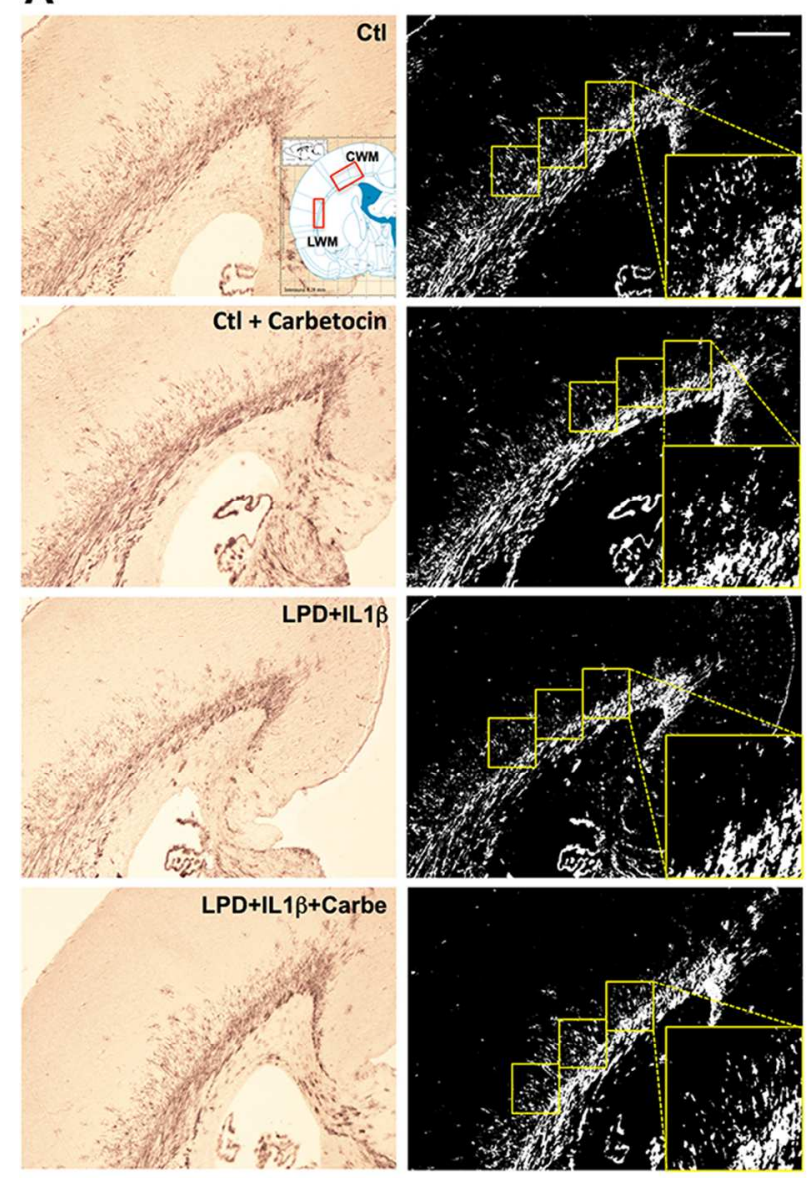

B

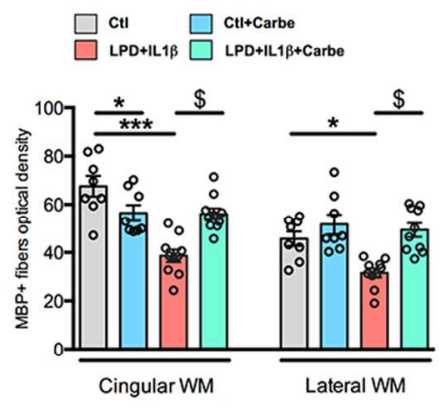

C

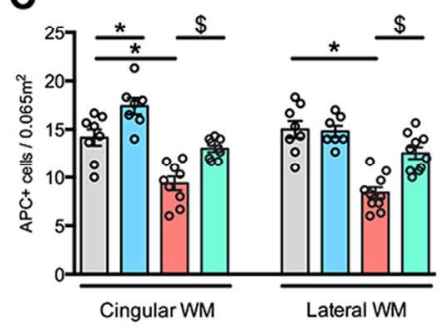

D

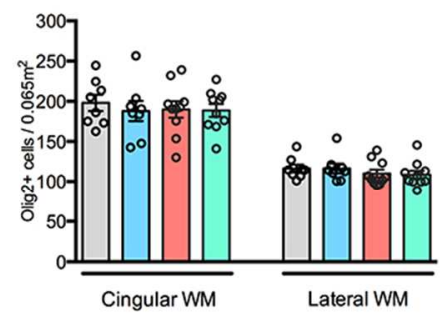

Figure 5: Consequences of LPD+IL1 $\beta$ and carbetocin treatment on myelination.

A. Representative photomicrographs of MBP immuno-reactivity assessment in the cingular and lateral white matter (CWM and LWM, respectively) in P10 animals. B. Quantification of MBP, APC and Olig2 immunoreactivity in response to LPD+IL1 $\beta$ challenge and carbetocin treatment. Comparisons were performed using one-way ANOVA followed by Newman-Keuls multiple comparison tests when appropriate. $*$ and $\$$ is respect

to control and LPD $+\mathrm{IL} 1 \beta$ respectively. Data are means \pm SEM. (See Supplementary Table 1 for detailed numbers, $\mathrm{F}$ - and $\mathrm{p}$-values). 
A

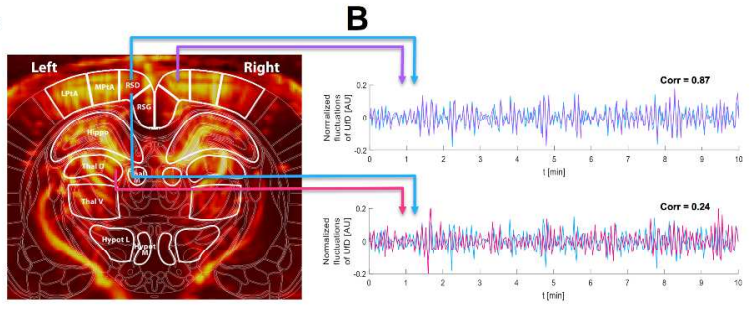

C

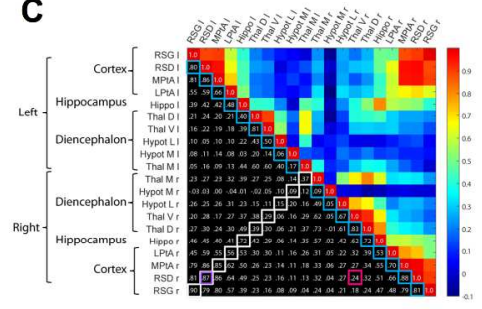

D

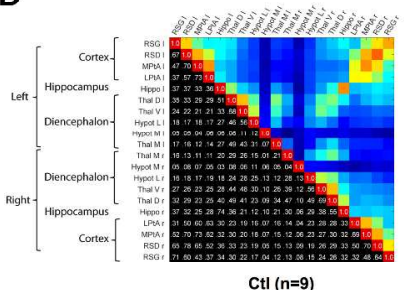

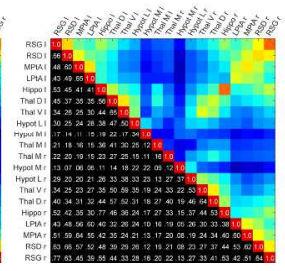

Ctl+Carbe $(n=7)$

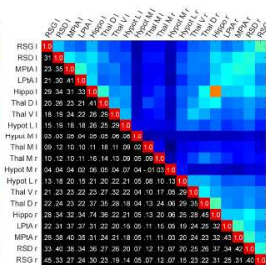

LPD+IL1 $1 \beta$ (n=9)

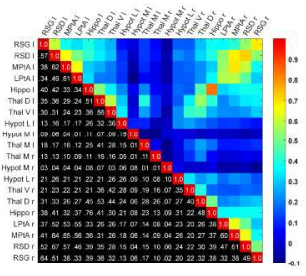

LPD+IL1 $\beta+$ Carbe $(n=9)$

E

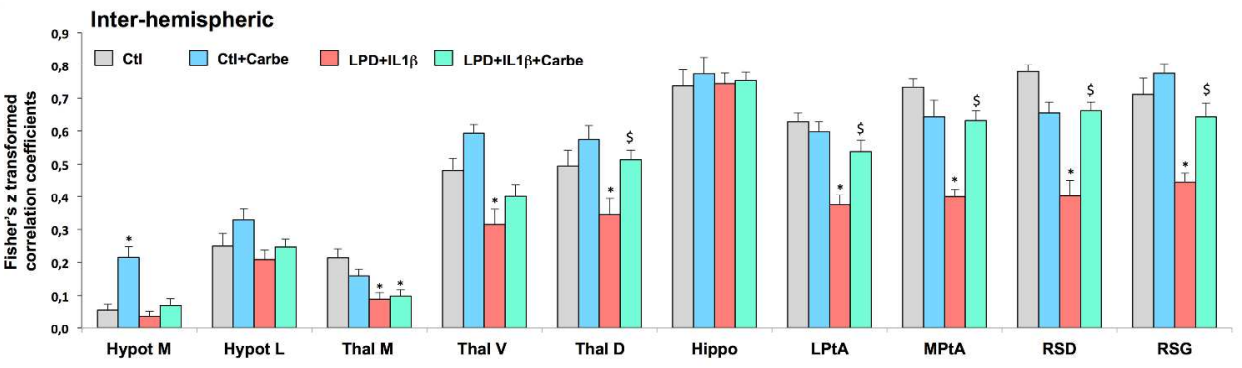

$\mathbf{F}$

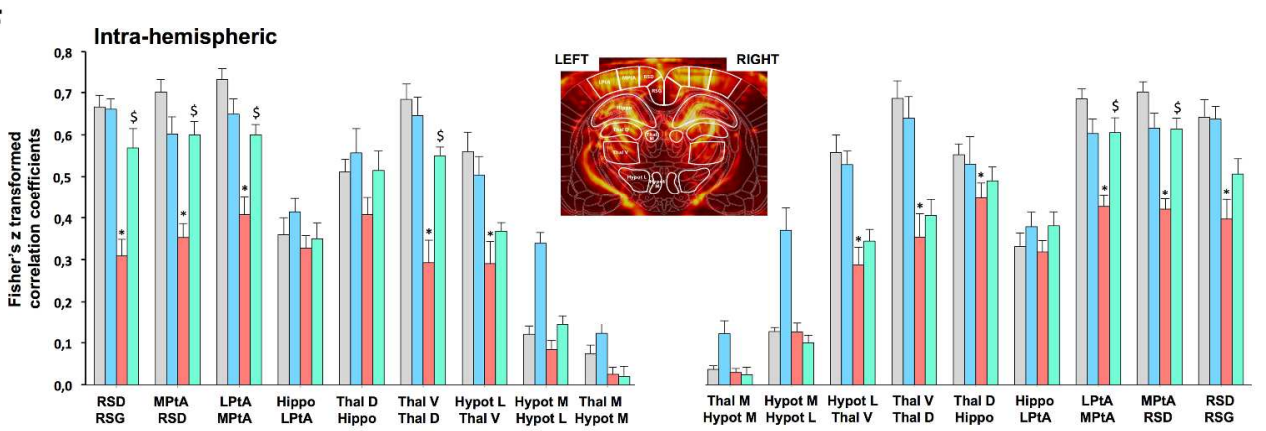

Figure 6: Consequences of LPD+IL1 $\beta$ and carbetocin treatment on myelination and functional intrinsic connectivity of the brain.

A. fUS imaging consists in the 300 repetitions of UfD image acquired every $2 \mathrm{~s}$, resulting in 10 minutes of resting state imaging data performed two times consecutively for each animal. Intensity in one pixel of a UfD image is proportional to the local blood volume. These images were registered with a functional rat brain atlas for further regions of interest (ROIs) based subdivision. B. Based on this registration 10 ROIs were delineated on each side, resulting in a total of 20 ROIs overall. In each of these regions the UfD signal was spatially averaged and temporally normalized to calculate Pearson correlation coefficient between every couple of signals. In this example, RSD signal is strongly similar on the left and right side (blue and purple signals), resulting in a high correlation coefficient (0.87), whereas correlation is quite weak between left

RSD and left ventral thalamus (blue and pink signals)(corr $=0.24$ ), this being interpreted as a low connectivity at that moment between those 2 cerebral structures. C. All these correlation coefficients were gathered into a matrix whose levels and spatial patterns reflect a degree of cerebral connectivity that can be 
compared between groups. This matrix is symmetrical, and one half is displayed as color for qualitative visual inspection and the other half is displayed as numerical values. The coefficients framed in white correspond to the so-called inter-hemispheric connectivity and the coefficients framed in blue correspond to the so-called intra-hemispheric connectivity (that can therefore be assessed on both left and right side). D. Average functional connectivity map in the control and LPD+IL1 $\beta$ animals treated or not with carbetocin. Pearson correlation coefficients are indicated for the right and left hemisphere in the cortex (RSG, retrosplenial granular cortex; RSD, retrosplenial dysgranular cortex; MPtA, medial parietal association cortex; LPtA, lateral parietal association cortex), in the hippocampus (Hippo), in the dorsal, ventral and medial thalamic area (Thal D, Thal V and Thal $\mathrm{M}$, respectively) and in medial and lateral hypothalamic area (Hypot $M$ and Hypot $L$, respectively). $E, F$. Loss of inter-(E) and Intra-(F) hemispheric functional intrinsic connectivity in LPD+IL1 $\beta$ animals and correction by early carbetocin treatment. For statistical analyses, matrix Pearson coefficients were transformed using a Fisher transformation. Comparisons were performed using one-way ANOVA followed by Newman-Keuls multiple comparison tests; * and $\$$ is respect to control and LPD + IL1 $\beta$ respectively. Data are means \pm SEM. (See Supplementary Table 1 for detailed numbers, Fand $\mathrm{p}$-values). 
A
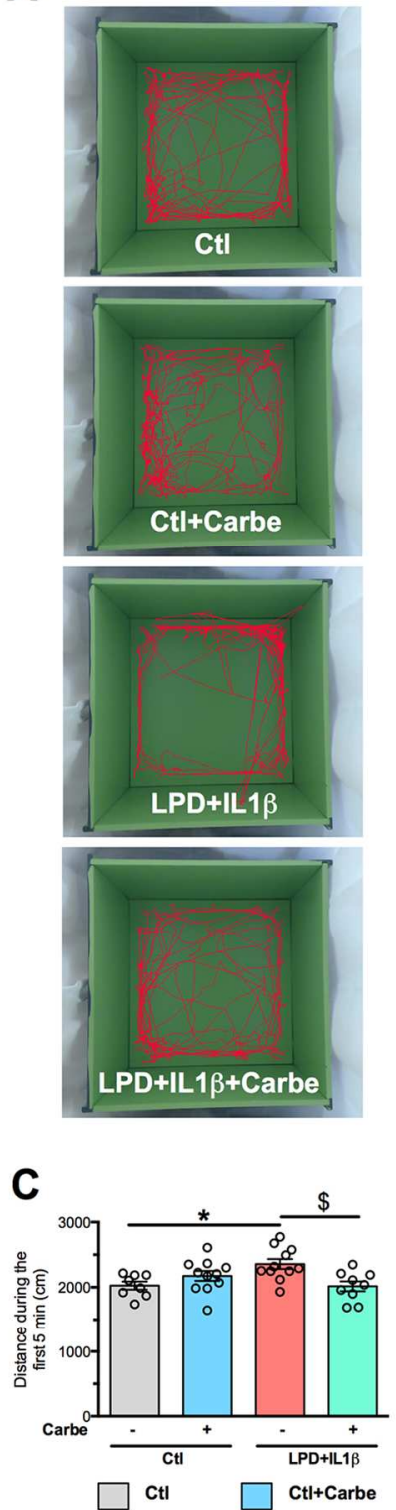

B
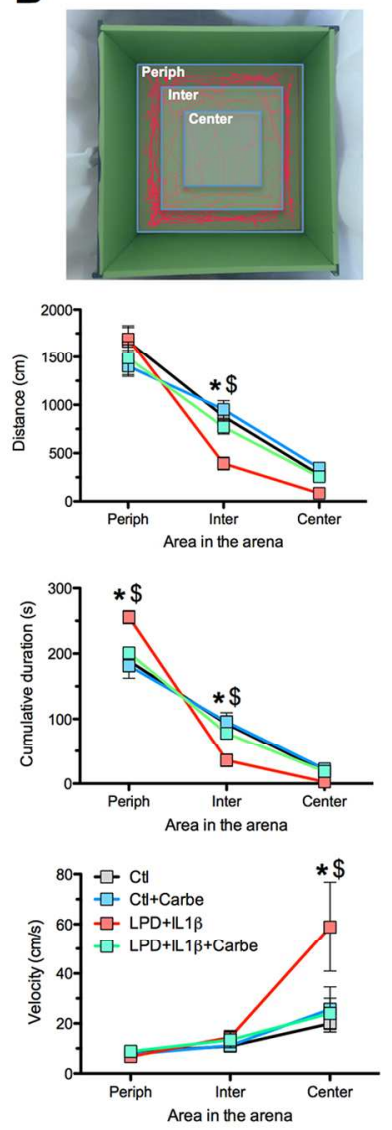

D

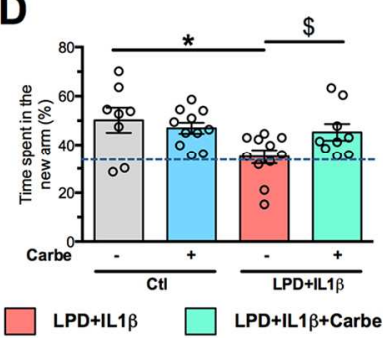

Figure 7: Behavioral consequences of LPD+IL1 $\beta$ and carbetocin treatment in juvenile and adult animals. A. Representative track records in the open field (OF) test performed in the 4 experimental groups in 28days old animals. B. Subdivision of the open field area in three complementary zones defines as periphery

(Periph), intermediate (Inter) and center. All comparisons were performed using two-way ANOVA for repeated measures, followed by Bonferroni multiple comparison tests when appropriate, $*$ is respect to control, $\$$ respect to LPD+IL1 $\beta$. Data are means \pm SEM. (See Supplementary Table 1 for detailed numbers, F- and p-values). C, D. Behavior during the acquisition and the retention tasks of the Y-maze performed in the 4 experimental groups in 2 months old animals. Distance traveled during the 5 first minutes of the 15 minutes of habituation period during which only two arms of the Y-maze are available (C). Percentage of time spent in the novel arm during the retention task of the Y-maze, 3 hours after the acquisition (D).

Comparisons were performed using one-way ANOVA followed by Newman-Keuls multiple comparison tests;

$*$ and $\$$ is respect to control and LPD+IL1 $\beta$ respectively. Data are means \pm SEM. (See Supplementary Table 1 for detailed numbers, $F$ - and $p$-values). 
Page 46 of 54 
Table 1 : Functional network enrichment based on sorted microglia cells transcript analysis in LPD+IL1 $\beta$ exposed animals compared to controls. Networks which have significantly more interactions than expected are listed as biological processes, cellular components and KEGG pathways.

\begin{tabular}{|c|c|c|c|}
\hline \multicolumn{2}{|c|}{$\begin{array}{l}\text { Number of nodes : } 107 \\
\text { Number of edges : } 128 \\
\text { Average node degree }: 2.39 \\
\text { Average local clustering coefficient : } 0.449\end{array}$} & \multicolumn{2}{|c|}{$\begin{array}{l}\text { Expected number of edges : } 43 \\
\text { PPI enrichment } p \text {-value : } 0\end{array}$} \\
\hline \multicolumn{4}{|c|}{ Functional enrichments in the network } \\
\hline \multicolumn{4}{|c|}{ Biological process (GO) } \\
\hline Pathway ID & Pathway description & Count in gene set & False discovery rate \\
\hline GO:0002237 & $\begin{array}{l}\text { Response to molecule of } \\
\text { bacterial origin }\end{array}$ & 16 & $2.72 \mathrm{e}-09$ \\
\hline GO:0002682 & $\begin{array}{l}\text { Regulation of immune system } \\
\text { process }\end{array}$ & 30 & $2.72 \mathrm{e}-09$ \\
\hline GO:0009607 & Response to biotic stimulus & 23 & $2.72 \mathrm{e}-09$ \\
\hline GO:0009617 & Response to bacterium & 19 & $2.72 \mathrm{e}-09$ \\
\hline GO:0051707 & Response to other organism & 22 & $2.72 \mathrm{e}-09$ \\
\hline \multicolumn{4}{|c|}{ Cellular Component (GO) } \\
\hline Pathway ID & Pathway description & Count in gene set & False discovery rate \\
\hline GO:0005764 & Lysosome & 15 & $1.63 e-05$ \\
\hline GO:0005829 & Cytosol & 35 & 0.000789 \\
\hline GO:0044437 & Vacuole part & 10 & 0.00512 \\
\hline GO:0043202 & Lysosomal lumen & 5 & 0.0161 \\
\hline \multicolumn{4}{|c|}{ KEGG Pathways } \\
\hline Pathway ID & Pathway description & Count in gene set & False discovery rate \\
\hline 04142 & Lysosome & 12 & $4.22 \mathrm{e}-10$ \\
\hline 00531 & $\begin{array}{l}\text { Glycosaminoglycan } \\
\text { degradation }\end{array}$ & 4 & 0.000363 \\
\hline 04380 & Osteoclast differentiation & 7 & 0.000363 \\
\hline 04210 & Apoptosis & 6 & 0.000372 \\
\hline 05152 & Tuberculosis & 7 & 0.0018 \\
\hline
\end{tabular}




\begin{tabular}{|l|l|l|}
\hline & & \\
\hline Figure 1 & Variable & \multicolumn{1}{c}{ Student's t-test } \\
\hline 1B & AVP & \\
\hline 1B & CRH & $\mathrm{t}_{21}=2.89$ \\
\hline 1B & OXT & $\mathrm{t}_{21}=2.551$ \\
\hline 1B & OXTR & $\mathrm{t}_{21}=3.448$ \\
\hline 1B & P2, IL1B & $\mathrm{t}_{21}=4.017$ \\
\hline 1B & P2, IL6 & $\mathrm{t}_{15}=3.038$ \\
\hline 1B & P2, TNFa & $\mathrm{t}_{14}=5.029$ \\
\hline 1B & P2, iNOS & $\mathrm{t}_{15}=6.342$ \\
\hline 1B & P2, GR & $\mathrm{t}_{13}=3.136$ \\
\hline 1B & P2, MR & $\mathrm{t}_{12}=3.96$ \\
\hline 1B & P4, IL-1B & $\mathrm{t}_{13}=2.776$ \\
\hline 1B & P4, IL6 & $\mathrm{t}_{14}=2.679$ \\
\hline 1B & P4, TNFa & $\mathrm{t}_{14}=2.44$ \\
\hline 1B & P4, iNOS & $\mathrm{t}_{14}=3.057$ \\
\hline 1B & P4, GR & $\mathrm{t}_{12}=2.216$ \\
\hline 1B & P4, MR & $\mathrm{t}_{10}=4.513$ \\
\hline 1B & P4, Iba1 & $\mathrm{t}_{10}=2.72$ \\
\hline 1B & P10, MBP cing & $\mathrm{t}_{11}=4.684$ \\
\hline 1B & P10, MBP lat & $\mathrm{t}_{16}=6.052$ \\
\hline 1B & P10, APC cing & $\mathrm{t}_{16}=4.167$ \\
\hline 1B & P10, APC lat & $\mathrm{t}_{15}=4.362$ \\
\hline & & $\mathrm{t}_{15}=6.469$ \\
\hline
\end{tabular}

\begin{tabular}{|l|l|l|}
\hline & & \multicolumn{1}{|c|}{ ANOVA } \\
\hline Figure 2 & Variable & \multicolumn{1}{c|}{ F-values } \\
\hline 2B & Iba1 & 1-way anova $\mathrm{F}_{3,21}=20.59$ \\
\hline 2C & IL1 $\beta$ & 1-way anova $\mathrm{F}_{3,31}=8.278$ \\
\hline CC & IL6 & 1-way anova $\mathrm{F}_{3,30}=10.26$ \\
\hline 2C & TNFa & 1-way anova $\mathrm{F}_{3,29}=26.22$ \\
\hline 2C & iNOS & 1-way anova $\mathrm{F}_{3,29}=10.26$ \\
\hline 2C & Arg1 & 1-way anova $\mathrm{F}_{3,31}=4.982$ \\
\hline 2C & IGF1 & 1-way anova $\mathrm{F}_{3,31}=9.97$ \\
\hline 2C & Mrc1 & 1-way anova $\mathrm{F}_{3,30}=55.34$ \\
\hline 2C & Sphk1 & 1-way anova $\mathrm{F}_{3,30}=8.664$ \\
\hline
\end{tabular}




\begin{tabular}{|l|l|l|}
\hline Figure 3 & Variable & \\
\hline 3B & IL1 $\alpha$ & t-values \\
\hline 3B & IL1 $\beta$ & $\mathrm{t}_{9}=3.744$ \\
\hline 3B & TNF & $\mathrm{t}_{9}=2.374$ \\
\hline 3B & IFN & $\mathrm{t}_{9}=2.276$ \\
\hline 3B & IL12 & $\mathrm{t}_{9}=2.981$ \\
\hline 3B & IL4 & $\mathrm{t}_{9}=0.358$ \\
\hline
\end{tabular}

\begin{tabular}{|l|l|l|}
\hline & & \multicolumn{1}{c}{ ANOVA } \\
\hline Figure 3 & Variable & \multicolumn{1}{c|}{ F-values } \\
\hline $3 \mathrm{C}$ & cells area & 2-way anova, interaction $\mathrm{F}_{2,1291}=21,81$ \\
\hline $3 \mathrm{C}$ & cells perimeter & 2-way anova, interaction $\mathrm{F}_{2,1291}=21,21$ \\
\hline $3 \mathrm{C}$ & cells circularity & 2-way anova, interaction $\mathrm{F}_{2,1291}=9.979$ \\
\hline $3 \mathrm{D}$ & <31 $\mu \mathrm{m}^{2}$ & 2-way anova, interaction $\mathrm{F}_{2,614}=2.419$ \\
\hline $3 \mathrm{D}$ & trom 31 $\mu^{2}$ to $45 \mu \mathrm{m}^{2}$ & 2-way anova, interaction $\mathrm{F}_{2,423}=0.336$ \\
\hline $3 \mathrm{D}$ & $>45 \mu \mathrm{m}^{2}$ & 2-way anova, interaction $\mathrm{F}_{2,242}=2.851$ \\
\hline
\end{tabular}

\begin{tabular}{|l|l|c|}
\hline & & \multicolumn{1}{c}{ ANOVA } \\
\hline & & \\
Figure 3 & Variable & F-values \\
\hline $3 \mathrm{~F}$ & TNFa & 2-way anova, interaction $\mathrm{F}_{3,67}=14.32$ \\
\hline $3 \mathrm{~F}$ & IL6 & 2-way anova, interaction $\mathrm{F}_{3,67}=16.32$ \\
\hline 3F & iNOS & 2-way anova, interaction $\mathrm{F}_{3,72}=10.69$ \\
\hline
\end{tabular}

\begin{tabular}{|c|c|c|}
\hline & & ANOVA \\
\hline Figure 4 & Variable & F-values \\
\hline 4D & IL1 $\beta$ & 1 -way anova $F_{3,20}=14.92$ \\
\hline 4D & TNF $\alpha$ & 1 -way anova $F_{3,20}=15.19$ \\
\hline 4D & IL-8 & 1 -way anova $F_{3,20}=20.6$ \\
\hline $4 \mathrm{~F}$ & cells surface & 1 -way anova $F_{3,34}=66.18$ \\
\hline $4 \mathrm{~F}$ & cells volume & 1 -way anova $F_{3,34}=11.56$ \\
\hline $4 \mathrm{~F}$ & area/volume ratio & 1 -way anova $F_{3,34}=14.98$ \\
\hline $4 \mathrm{~F}$ & sphericity & 1 -way anova $F_{3,34}=107$ \\
\hline $4 G$ & filopode speed & 1-way anova $F_{3,8}=194.3$ \\
\hline $4 \mathrm{H}$ & filopode displacement length & 1-way anova $F_{3,8}=3789$ \\
\hline
\end{tabular}




\begin{tabular}{|c|c|c|}
\hline & & ANOVA \\
\hline Figure 5 & Variable & F-values \\
\hline $5 \mathrm{~B}$ & MBP cing & 1 -way anova $F_{3,32}=15.58$ \\
\hline $5 B$ & MBP lat & 1-way anova $F_{3,32}=9.89$ \\
\hline $5 \mathrm{C}$ & APC cing & 1-way anova $F_{3,29}=21.82$ \\
\hline $5 \mathrm{C}$ & APC lat & 1-way anova $F_{3,29}=21.5$ \\
\hline $5 \mathrm{D}$ & Olig2 cing & 1-way anova $F_{3,32}=0.1949$ \\
\hline $5 \mathrm{D}$ & Olig2 lat & 1-way anova $F_{3,32}=0.6268$ \\
\hline & & ANOVA \\
\hline Figure 6 & Variable & F-values \\
\hline $6 \mathrm{E}$ & Hypot M & 1 -way anova $F_{3,30}=13.35$ \\
\hline $6 \mathrm{E}$ & Hypot L & 1 -way anova $F_{3,30}=2.312$ \\
\hline $6 \mathrm{E}$ & Thal M & 1-way anova $F_{3,30}=7.092$ \\
\hline $6 \mathrm{E}$ & Thal V & 1-way anova $F_{3,30}=8.665$ \\
\hline $6 \mathrm{E}$ & Thal D & 1 -way anova $F_{3,30}=5.123$ \\
\hline $6 \mathrm{E}$ & Hippo & 1-way anova $F_{3,30}=0.1386$ \\
\hline $6 \mathrm{E}$ & LPtA & 1 -way anova $F_{3,30}=13.76$ \\
\hline $6 \mathrm{E}$ & MPtA & 1-way anova $F_{3,30}=20.98$ \\
\hline $6 \mathrm{E}$ & RSD & 1 -way anova $F_{3,30}=23.44$ \\
\hline $6 \mathrm{E}$ & RSG & 1 -way anova $F_{3,30}=13.1$ \\
\hline $6 \mathrm{~F}$ & left RSD-RSG & 1 -way anova $F_{3,30}=21.26$ \\
\hline $6 \mathrm{~F}$ & left MPtA-RSD & 1-way anova $\mathrm{F}_{3,30}=20.84$ \\
\hline $6 \mathrm{~F}$ & left LPtA-MPtA & 1-way anova $F_{3,30}=18.88$ \\
\hline $6 \mathrm{~F}$ & left Hippo-LPtA & 1-way anova $F_{3,30}=0.9238$ \\
\hline $6 \mathrm{~F}$ & left Thal D-Hippo & 1-way anova $F_{3,30}=2.13$ \\
\hline $6 \mathrm{~F}$ & left Thal V-Thal D & 1-way anova $F_{3,30}=19.26$ \\
\hline $6 \mathrm{~F}$ & left Hypot L-Thal V & 1-way anova $F_{3,30}=8.763$ \\
\hline $6 \mathrm{~F}$ & left Hypot M-Hypot L & 1-way anova $F_{3,30}=24.05$ \\
\hline $6 \mathrm{~F}$ & left Thal M-Hypot M & 1 -way anova $F_{3,30}=4.48$ \\
\hline $6 \mathrm{~F}$ & right Thal M-Hypot M & 1-way anova $F_{3,30}=5.736$ \\
\hline $6 \mathrm{~F}$ & right Hypot M-Hypot L & 1-way anova $F_{3,30}=18.67$ \\
\hline $6 \mathrm{~F}$ & right Hypot L-Thal V & 1-way anova $F_{3,30}=13.16$ \\
\hline $6 \mathrm{~F}$ & right Thal V-Thal D & 1-way anova $F_{3,30}=12.64$ \\
\hline $6 \mathrm{~F}$ & right Thal D-Hippo & 1 -way anova $F_{3,30}=1.337$ \\
\hline $6 \mathrm{~F}$ & right Hippo-LPtA & 1-way anova $F_{3,30}=1.018$ \\
\hline
\end{tabular}




\begin{tabular}{|l|l|l|}
\hline $6 \mathrm{~F}$ & right LPtA-MPtA & 1 -way anova $\mathrm{F}_{3,30}=14.15$ \\
\hline $6 \mathrm{~F}$ & right MPtA-RSD & 1 -way anova $\mathrm{F}_{3,30}=20.2$ \\
\hline $6 \mathrm{~F}$ & right RSD-RSG & 1 -way anova $\mathrm{F}_{3,30}=8.403$ \\
\hline
\end{tabular}

\begin{tabular}{|l|l|l|}
\hline & & \multicolumn{1}{c}{ ANOVA } \\
\hline Figure 7 & Variable & \multicolumn{1}{c|}{ F-values } \\
\hline 7B & Distance traveled & 2-way anova, interaction $\mathrm{F}_{6,20}=2.871$ \\
\hline 7B & Cumulative duration & 2-way anova, interaction $\mathrm{F}_{6,20}=5.641$ \\
\hline 7B & Shifting velocity & 2-way anova, interaction $\mathrm{F}_{6,20}=3.348$ \\
\hline 7C & Distance traveled & 1-way anova $\mathrm{F}_{3,35}=4.699$ \\
\hline 7D & time spent in the novel arm & 1-way anova $\mathrm{F}_{3,35}=4.016$ \\
\hline
\end{tabular}




\begin{tabular}{|l|r|r|}
\hline & \multicolumn{2}{|c|}{ N=number of animals } \\
\hline p-values & Control & LPD+IL1 $\boldsymbol{r}$ \\
\hline$P=0.009$ & 11 & 12 \\
\hline$P=0.02$ & 11 & 12 \\
\hline$P=0.002$ & 11 & 12 \\
\hline$P=0.0006$ & 11 & 12 \\
\hline$P=0.008$ & 8 & 9 \\
\hline$P=0.0002$ & 8 & 8 \\
\hline$P<0.0001$ & 8 & 9 \\
\hline$P=0.008$ & 7 & 8 \\
\hline$P=0.002$ & 7 & 7 \\
\hline$P=0.015$ & 8 & 7 \\
\hline$P=0.02$ & 8 & 8 \\
\hline$P=0.03$ & 8 & 8 \\
\hline$P=0.009$ & 8 & 8 \\
\hline$P=0.046$ & 7 & 7 \\
\hline$P=0.001$ & 6 & 9 \\
\hline$P=0.02$ & 6 & 10 \\
\hline$P=0.0007$ & 6 & 6 \\
\hline$P<0.0001$ & 8 & 6 \\
\hline$P=0.0007$ & 8 & 7 \\
\hline$P=0.0006$ & 8 & 9 \\
\hline$P<0.0001$ & & 9 \\
\hline & & 8 \\
\hline
\end{tabular}

\begin{tabular}{|l|r|r|r|r|}
\hline & \multicolumn{5}{|c|}{ N=number of animals } \\
\hline p-values & Control & $\begin{array}{c}\text { Control } \\
\text { +carbetocin }\end{array}$ & LPD+IL1 $\beta$ & $\begin{array}{c}\text { LPD+IL1 } \beta \\
+ \text { carbetocin }\end{array}$ \\
\hline$P<0.0001$ & 6 & 6 & 7 & 6 \\
\hline$P=0.0003$ & 8 & 8 & 10 & 9 \\
\hline$P<0.0001$ & 8 & 8 & 10 & 8 \\
\hline$P<0.0001$ & 8 & 7 & 10 & 9 \\
\hline$P<0.0001$ & 7 & 7 & 10 & 9 \\
\hline$P=0.0062$ & 8 & 7 & 10 & 9 \\
\hline$P<0.0001$ & 8 & 8 & 10 & 9 \\
\hline$P<0.0001$ & 8 & 7 & 10 & 10 \\
\hline$P=0.0003$ & 8 & 7 & & 9 \\
\hline
\end{tabular}




\begin{tabular}{|c|c|c|}
\hline p-values & Control & LPD+IL1 $\beta$ \\
\hline$P=0.0046$ & 6 & 5 \\
\hline$P=0.0416$ & 6 & 5 \\
\hline$P=0.0489$ & 5 & 6 \\
\hline$P=0.0179$ & 6 & 5 \\
\hline$P=0.7284$ & 5 & 6 \\
\hline$P=0.0412$ & 6 & 6 \\
\hline
\end{tabular}

\begin{tabular}{|c|c|c|c|c|}
\hline & & & \multicolumn{2}{|c|}{$\mathrm{N}=$ number of cells assessed } \\
\hline & \multicolumn{3}{|c|}{ Control } & \\
\hline p-values & Basal & IL1 $\beta+I N F Y$ & $\begin{array}{l}\text { IL1 } \beta+I N F Y^{+} \\
\text {Carbetocin }\end{array}$ & Basal \\
\hline $\mathrm{P}<0.0001$ & 204 & 224 & 190 & 243 \\
\hline$P<0.0001$ & 204 & 224 & 190 & 243 \\
\hline$P<0.0001$ & 204 & 224 & 190 & 243 \\
\hline$P=0.0898$ & 68 & 144 & 84 & 132 \\
\hline$P=0.7147$ & 68 & 63 & 51 & 77 \\
\hline$P=0.0597$ & 68 & 17 & 55 & 34 \\
\hline
\end{tabular}

\begin{tabular}{|c|c|c|c|c|}
\hline & & & & $\mathrm{N}=$ number of $\mathrm{c \epsilon}$ \\
\hline & \multicolumn{4}{|c|}{ Control } \\
\hline p-values & Basal & IL1 $\beta+I N F Y$ & $\begin{array}{c}\text { IL1 } \beta+\text { INFY } \\
\text { +carbetocin }\end{array}$ & $\begin{array}{c}\text { IL1 } \beta+\text { INFY } \\
\text { +carbetocin } \\
\text { +L-368-899 }\end{array}$ \\
\hline$P<0.0001$ & 11 & 10 & 9 & 7 \\
\hline$P<0.0001$ & 12 & 10 & 11 & 7 \\
\hline$P<0.0001$ & 9 & 9 & 12 & 12 \\
\hline
\end{tabular}

\begin{tabular}{|l|r|r|r|r|}
\hline & \multicolumn{4}{|c|}{$\mathbf{N}=\mathbf{m R N A}$ extracts with 15 pooled embryos per extract } \\
\hline p-values & Control & \multicolumn{1}{|c|}{$\begin{array}{c}\text { Control } \\
\text { +carbetocin }\end{array}$} & Hydrocortisone & $\begin{array}{c}\text { Hydrocortisone+ } \\
\text { carbetocin }\end{array}$ \\
\hline$P<0.0001$ & 8 & 6 & 4 & 6 \\
\hline$P<0.0001$ & 8 & 6 & 4 & 6 \\
\hline$P<0.0001$ & 8 & 6 & 4 & $9,(30)$ \\
\hline & N =number of embryos (n=total number of microglia assessed) \\
\hline$P<0.0001$ & $11,(26)$ & $9,(37)$ & $9,(25)$ & $9,(30)$ \\
\hline$P<0.0001$ & $11,(26)$ & $9,(37)$ & $9,(25)$ & $9,(30)$ \\
\hline$P<0.0001$ & $11,(26)$ & $9,(37)$ & $9,(25)$ & $9,(30)$ \\
\hline$P<0.0001$ & $11,(26)$ & $9,(37)$ & $9,(25)$ & $3,(329)$ \\
\hline$P<0.0001$ & $3,(174)$ & $3,(115)$ & $3,(148)$ & $3,(329)$ \\
\hline$P<0.0001$ & $3,(174)$ & $3,(115)$ & $3,(148)$ & \\
\hline
\end{tabular}




\begin{tabular}{|c|c|c|c|c|}
\hline & \multicolumn{4}{|c|}{$\mathrm{N}=$ number of animals } \\
\hline p-values & Control & \begin{tabular}{c|} 
Control \\
+ carbetocin
\end{tabular} & LPD+IL1 $\beta$ & $\begin{array}{c}\text { LPD+IL1 } \beta \\
\text { +carbetocin }\end{array}$ \\
\hline$P<0.0001$ & 8 & 8 & 10 & 10 \\
\hline$P<0.0001$ & 8 & 8 & 10 & 10 \\
\hline$P<0.0001$ & 8 & 7 & 9 & 9 \\
\hline$P<0.0001$ & 8 & 7 & 9 & 9 \\
\hline$P=0.8991$ & 8 & 8 & 10 & 10 \\
\hline$P=0.603$ & 8 & 8 & 10 & 10 \\
\hline & \multicolumn{4}{|c|}{$\mathrm{N}=$ number of animals } \\
\hline p-values & Control & \begin{tabular}{c|} 
Control \\
+ carbetocin
\end{tabular} & LPD+IL1 $\beta$ & $\begin{array}{c}\text { LPD+IL1 } \beta \\
\text { +carbetocin }\end{array}$ \\
\hline$P<0.0001$ & 9 & 7 & 9 & 9 \\
\hline$P=0.0962$ & 9 & 7 & 9 & 9 \\
\hline$P=0.001$ & 9 & 7 & 9 & 9 \\
\hline$P=0.0003$ & 9 & 7 & 9 & 9 \\
\hline$P=0.0056$ & 9 & 7 & 9 & 9 \\
\hline$P=0.9361$ & 9 & 7 & 9 & 9 \\
\hline$P<0.0001$ & 9 & 7 & 9 & 9 \\
\hline$P<0.0001$ & 9 & 7 & 9 & 9 \\
\hline$P<0.0001$ & 9 & 7 & 9 & 9 \\
\hline$P<0.0001$ & 9 & 7 & 9 & 9 \\
\hline $\mathrm{P}<0.0001$ & 9 & 7 & 9 & 9 \\
\hline$P<0.0001$ & 9 & 7 & 9 & 9 \\
\hline$P<0.0001$ & 9 & 7 & 9 & 9 \\
\hline$P=0.4413$ & 9 & 7 & 9 & 9 \\
\hline$P=0.1172$ & 9 & 7 & 9 & 9 \\
\hline$P<0.0001$ & 9 & 7 & 9 & 9 \\
\hline$P=0.0003$ & 9 & 7 & 9 & 9 \\
\hline$P<0.0001$ & 9 & 7 & 9 & 9 \\
\hline$P=0.0103$ & 9 & 7 & 9 & 9 \\
\hline$P=0.0032$ & 9 & 7 & 9 & 9 \\
\hline$P<0.0001$ & 9 & 7 & 9 & 9 \\
\hline$P<0.0001$ & 9 & 7 & 9 & 9 \\
\hline$P<0.0001$ & 9 & 7 & 9 & 9 \\
\hline$P=0.281$ & 9 & 7 & 9 & 9 \\
\hline$P=0.3986$ & 9 & 7 & 9 & 9 \\
\hline
\end{tabular}




\begin{tabular}{|l|r|r|r|r|}
\hline$P<0.0001$ & 9 & 7 & 9 & 9 \\
\hline$P<0.0001$ & 9 & 7 & 9 & 9 \\
\hline$P=0.0003$ & 9 & 7 & 9 & 9 \\
\hline
\end{tabular}

\begin{tabular}{|l|r|c|r|r|}
\hline & \multicolumn{5}{|c|}{ N=number of animals } \\
\hline p-values & Control & $\begin{array}{c}\text { Control } \\
\text { +carbetocin }\end{array}$ & LPD+IL1 $\beta$ & $\begin{array}{c}\text { LPD+IL1 } \beta \\
+ \text { carbetocin }\end{array}$ \\
\hline$P=0.0202$ & 6 & 6 & 6 & 6 \\
\hline$P=0.0003$ & 6 & 6 & 6 & 6 \\
\hline$P=0.0091$ & 6 & 6 & 6 & 9 \\
\hline$P=0.0074$ & 8 & 11 & 11 & 9 \\
\hline$P=0.0148$ & 8 & 11 & 11 & \\
\hline
\end{tabular}


Page 56 of 54 


\begin{tabular}{|r|r|}
\hline \multicolumn{2}{|c|}{ LPD } \\
\hline \multicolumn{1}{|c|}{ IL1 $\beta+I N F Y$} & $\begin{array}{l}\text { IL1 } \beta+I N F \gamma^{+} \\
\text {Carbetocin }\end{array}$ \\
\hline 221 & 215 \\
\hline 221 & 215 \\
\hline 221 & 215 \\
\hline 117 & 75 \\
\hline 81 & 89 \\
\hline 23 & 51 \\
\hline
\end{tabular}

\begin{tabular}{|c|c|c|c|}
\hline :ll culture wells & & & \\
\hline & $\overline{L F}$ & & \\
\hline Basal & IL1 $\beta+I N F Y$ & $\begin{array}{c}\text { IL1 } 1 \beta+I N F Y \\
\text { +carbetocin }\end{array}$ & $\begin{array}{c}\text { IL1 } \beta+\text { INFY } \\
\text { +carbetocin } \\
\text { +L-368-899 }\end{array}$ \\
\hline 9 & 10 & 9 & 10 \\
\hline 10 & 9 & 8 & 8 \\
\hline 10 & 10 & 9 & 9 \\
\hline
\end{tabular}

